Asian-Australasian Journal of

Bioscience and Biotechnology

ISSN 2414-1283 (Print) 2414-6293 (Online)

www.ebupress.com/journal/aajbb

\title{
Article \\ Aqua medicines, drugs and chemicals (AMDC) used in freshwater aquaculture of South-Eastern Bangladesh
}

\author{
Amir Hossain $^{1 *}$, Saiful Islam ${ }^{2}$, Abdulla-Al-Asif ${ }^{3 *}$ and Hafzur Rahman ${ }^{4}$ \\ ${ }^{1}$ International Studies of Aquatic Tropical Ecology (ISATEC), Department of Biology, University of Bremen, \\ Bibliothekstraße 1, 28359 Bremen, Germany \\ ${ }^{2}$ Department of Fisheries and Marine Science, Noakhali Science and Technology University, Bangladesh \\ ${ }^{3}$ Department of Animal Science and Fisheries, Faculty of Agricultural Science and Forestry, Universiti Putra \\ Malaysia Bintulu Campus, 97008 Bintulu, Sarawak, Malaysia \\ ${ }^{4}$ Department of Fisheries Management, Faculty of Fisheries, Bangladesh Agricultural University, Mymensingh, \\ 2202, Bangladesh
}

*Corresponding author: Amir Hossain, International Studies of Aquatic Tropical Ecology (ISATEC), Department of Biology, University of Bremen, Bibliothekstraße 1, 28359 Bremen, Germany, amhnstu@gmail.com; and Abdulla-Al-Asif, Department of Animal Science and Fisheries, Faculty of Agricultural Science and Forestry, Universiti Putra Malaysia Bintulu Campus, 97008 Bintulu, Sarawak, Malaysia, jessoreboyhemel@gmail.com

Received: 07 July 2021/Accepted: 28 August 2021/ Published: 31 August 2021

Abstract: A broad variety of aquaculture-related medications, drugs, and chemicals (AMDC) are extensively
used in the aquaculture industry in South-Eastern Bangladesh. Fish farmers are worried about the quality of
their final product, and disease outbreaks must be stopped at all costs. Farmers are sometimes one ahead of the
curve when it comes to producing healthy final products by including probiotics, vitamins, and minerals into
their aquaculture setups to promote early and disease-free output. However, the current study was carried out in
south eastern Bangladesh, specifically in the highly dense aquaculture regions of Chandpur, Cumilla, and Feni
district ( 17 upazilas), from November 2016 to January 2018 . Questions were asked through interviews and a
Focus Group Discussion (FGD) was held to gather primary data. The major target groups were aquaculture
farmers, AMDC shops, pharmaceutical company employees, and hatchery owners. In this three-county area,
according to the findings from the thorough research, there are a total of 33 companies that advertise 330
generics brand products via their own distributional channels. Among the available AMDC products in the study
area, growth promoters were mostly abundant products among all categories while other products such as
predator removal products, insecticides and ectoparasiticides, water quality and pond management, plankton
producer, plankton bloom cleaner, disinfectant and disease treatment, toxic gas reducer, pH controller, oxygen
supply, stress reducer, growth promoter, probiotics and antibiotics were most selling products to the farmers.
The present study revealed 19 generic of antibiotics were available and prescribed by the AMDC vendors or
aquaculture disease consultants (ADC) around the regions. Additionally, the research also included the dosages
of AMDC and the method of administration in the aquaculture pond, which will assist both the farmers and the
ADC in selecting and suggesting the appropriate medications or treatments that may be beneficial to the farmers
in the long run.

Keywords: aquaculture; disease; treatments; antibiotics; probiotics; AMDC

\section{Introduction}

Despite the fact that it is the fastest-growing food-producing industry on the planet, aquaculture has surpassed all other animal-based food-producing industries in terms of growth (Froehlich et al., 2018; Leung and Bates, 2013). The fishery and aquaculture industries are critical to developing economy of Bangladesh, as they provide 
millions of jobs and generate constant worldwide export revenues for the country (Sunny et al., 2021). Bangladesh was the fifth-largest global producer of aquaculture products in 2018, and the aquaculture industry of Bangladesh is expected to grow in the next years (Shamsuzzaman et al., 2020, 2017). Agriculture in Bangladesh has evolved technologically and risen in size and scope over the last few decades, diversifying, intensifying, and diversifying further (Hinchliffe et al., 2021; Naylor et al., 2021; Toufique and Belton, 2014).

In Bangladesh, freshwater aquaculture generally consists of pond aquaculture, particularly polyculture of both local and exotic species, whereas coastal aquaculture primarily consists of shrimp farming (Bostock et al., 2010; Boyd et al., 2020; Rahman et al., 2021). In recent years, there has been a considerable expansion of aquaculture in Bangladesh, even the mariculture is considering one of the major industries in upcoming years (AftabUddin et al., 2021; Al-Asif et al., 2021; Khan et al., 2021).

Aqua medicine, drugs and chemicals (AMDC) are increasingly being used in aquatic animal health management in Bangladesh as aquaculture expands (Al-Asif et al., 2021; Alam and Haque, 2021; Diana et al., 2013; Shamsuzzaman and Biswas, 2012). Much of this development has been focused on districts like Cumilla, Feni, Chandpur, Noakhali, where commercial Tilapia and carp polyculture culture is gaining momentum (Adhikary $e t$ al., 2018a; Bayazid, 2016; Hossain et al., 2013; Islam et al., 2019; Pravakar et al., 2013; Ullah et al., 2020a). Muhuri is the largest fish farming project in Feni district, encompassing the districts of Feni Sadar, Sonagazi, Chhagalnaiya, and Parshuram in Feni and Mirersarai in Chittagong. With the increase in aquaculture practices leading to enhanced fish production, aquatic animals have come across a series of health menaces due to environmental stress, the incursion of infectious pathogens and increased incidence of fish disease outbreaks (Assefa and Abunna, 2018; Biswas et al., 2018; Chowdhury et al., 2015; Kotob et al., 2016; Lafferty et al., 2015; Ullah et al., 2020a).

In Bangladesh and other Asian nations, many bacterial, viral, fungal, and parasite diseases have been observed in aquaculture (Adhikary et al., 2018b; Ahmed et al., 2007; Faruk et al., 2004; Hasan et al., 2014; Majumder et al., 2001; Shabuj et al., 2016; Sharif and Al-Asif, 2015; Siddique et al., 2021; Vaumik et al., 2017). A large number of aquaculture medicines and chemicals are currently being utilized to prevent production loss as a consequence of this phenomenon (Al-Asif et al., 2021; Chowdhury et al., 2015; Rahman et al., 2019; Ullah et al., 2020).

Besides the control of fish health, aqua medicines and chemicals are required for pond preparation, soil and water management, natural aquatic production improvement, feed formulation, and fish growth (Al-Asif $e t$ al., 2021; Chowdhury et al., 2015; Faruk et al., 2021; Hossain et al., 2014; Ullah et al., 2020a). Around 1484 aquamedicines generics are being found and commercialized by 100 pharmaceutical businesses over Bangladesh in past decade (Al-Asif et al., 2021). Many aquaculture consultants, representatives from pharmaceutical and feed companies, and chemical sellers are involved in the marketing chain for distributing such products to end-users (Al-Asif et al., 2021; Sharker et al., 2014). Lime, disinfection, rotenone, various inorganic and organic fertilizers, phostoxin, salt, dipterex, antimicrobials, potassium permanganate, copper sulphate, formalin, sumithion, melathion, and other chemicals are frequently employed in aquaculture of Bangladesh (Adhikary $e t$ al., 2018b; Al-Asif et al., 2021; Biswas et al., 2018; Chowdhury et al., 2015; Faruk et al., 2004; Rahman et al., 2019; Ullah et al., 2020a). The use of these chemicals in fish aquaculture units is currently being supported by a number of pharmaceutical companies and other chemical sellers, despite the fact that most farmers are completely unaware of the stability of drugs and effectiveness (Al-Asif et al., 2021; Lulijwa et al., 2020). In recent years, a number of international and national organizations have voiced significant concern about the overuse or abuse of these drugs, which has often led in the development of Antimicrobial Resistance (AMR), presenting a serious threat to public health (Cabello et al., 2013; Hoque et al., 2020; Lulijwa et al., 2020; Neela et al., 2015; Rasul and Majumdar, 2017; Thornber et al., 2019; Watts et al., 2017).

Fishermen are compelled to use a variety of aqua medicines and chemicals in a sequential manner, according to the effects of each drug or chemical. It is up to them to determine the dosage of chemicals based on their own expertise, product instructions on the bottle, or discussions with chemical suppliers or farmers (Al-Asif et al., 2021; Hasan et al., 2015). Consequently, appropriate doses of these aqua medicines and antibiotics are regularly ignored, presenting a danger to aquaculture as well as to the general public (Hinchliffe et al., 2018; Hoque et al., 2020; Liu et al., 2021; Reverter et al., 2020; Schar et al., 2021). Over the past decade, there has been a significant increase in the amount of information accessible regarding aquaculture drug use and its implications for human health, environmental protection, and the sector's long-term sustainability (Lulijwa et al., 2020).

As aquaculture grows in this area, more pesticides, antibiotics, and aqua medicine are required to keep it running well (Al-Asif et al., 2021). The area, on the other hand, has not had a comprehensive study of the marketing and availability of different aquaculture medicines, pharmaceuticals, and chemicals performed in order to determine their availability (Al-Asif et al., 2021; Rahman et al., 2019; Ullah et al., 2020a). As a 
consequence, the present study investigated the market availability and use patterns of different aqua-medicines, pharmaceuticals, chemicals, and formulations in the major aquaculture zones of Bangladesh.

\section{Materials and methods}

\subsection{Study area and periods}

The data were collected from three district of south east Bangladesh namely, Cumilla, Chandpur, and Feni district (Figure 1). A total 17 upazilas (sub-district) were selected for conducting the survey from November 2016 to January 2018. The study covered nine upazila, namely Comilla Sadar, Comilla Sadar Dakkhin, Daudkandi, Muradnagar, Brahmanpara, Burichang, Chauddagram, Laksam and Barura upazilla from Cumilla district; four upazila viz. Chandpur Sadar, Hajigonj, Faridganj and Matlab Uttar upazila from Chandpur district, while four upazila were considered from Feni district such as, Feni sadar, Sonagazi, Parshuram, and Daganbhuiyan (Figure 1).

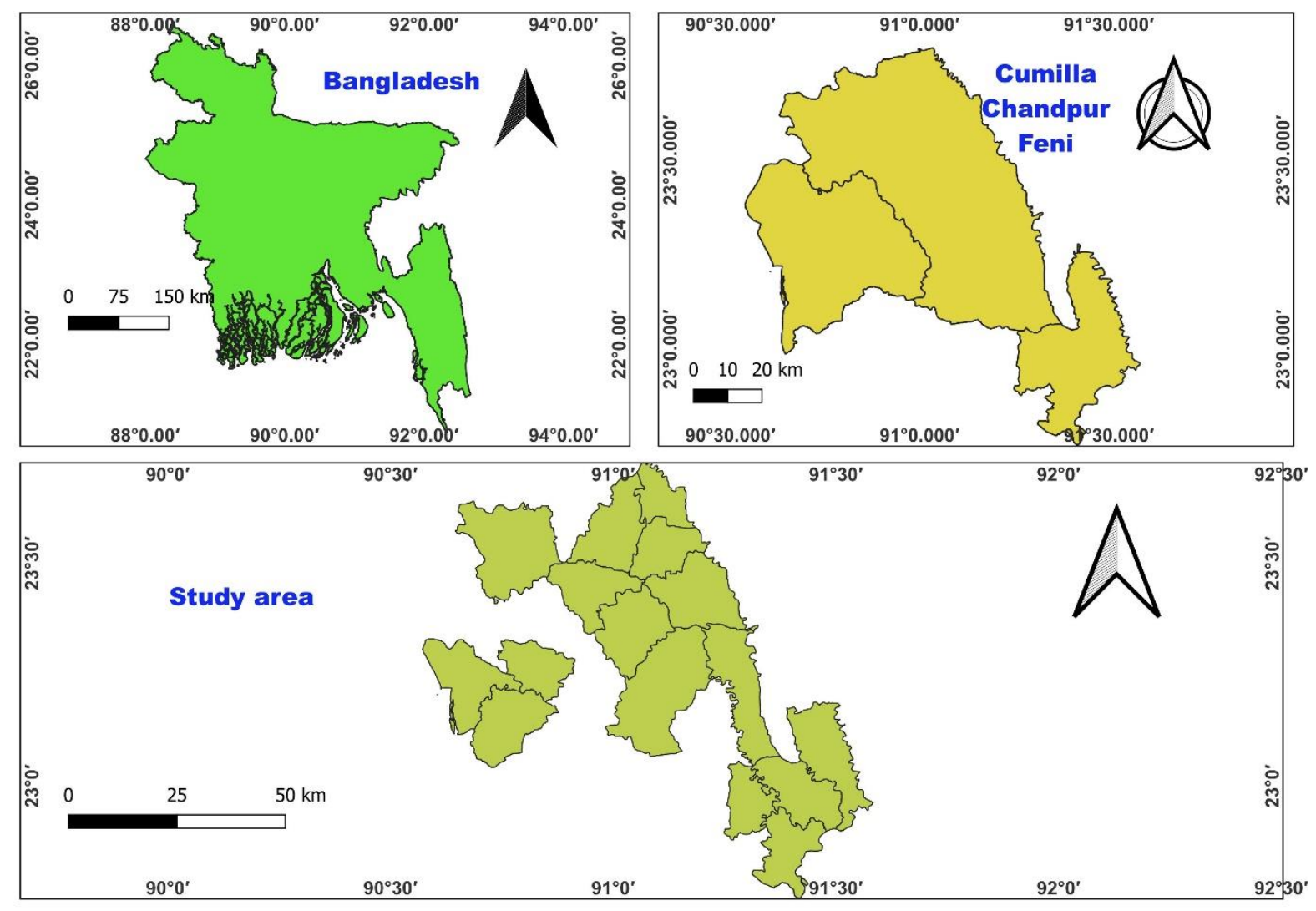

Figure 1. The study covered three south eastern districts of Bangladesh.

\subsection{Data collection}

Data were collected from fish farms, feed shops, aqua shops and medical representative of Pharmaceuticals companies at their offices. Both primary and secondary data were used to finalize the study process. Several survey techniques were adopted for gathering data, such as face-to-face interview, focus group discussion (FGD), Participatory Rural Appraisal (PRA) and so on to gather the aqua medicines, drugs and chemicals (AMDC) status in the market, fish disease in the farms, business strategies by the AMDC companies and their representatives.

\subsubsection{Primary data collection}

First-hand information was gathered through questionnaire interviews with representatives from culture farms, chemical merchants, and medical representatives from pharmaceutical companies. During the visit to the nurseries and culture pond, the following aspects of chemicals and fish toxicants were considered important: the purpose of using chemicals or toxicants, variations in application methods, effectiveness of chemicals or toxicants, and toxicants, variation in applied dose of chemicals or toxicants, or toxicants by the government and availability of the chemicals, specific toxicity of the chemicals, and specific toxicity of the toxicants. 


\subsubsection{Questionnaire interviews}

The questionnaire form was filled in by interviewing from 157 farmers, 105 chemical sellers and 33 medical representatives of Pharmaceuticals Company directly from the study area.

\subsubsection{Focus Group Discussion (FGD)}

For this study, one of the PRA tool such as Focus Group Discussion (FGD) was conducted in fish farms ( $\mathrm{n}=20$ ), hatcheries or gher owner $(n=10)$, fish farmers, chemical sellers $(n=135)$, and medical representatives $(n=50)$ of Pharmaceuticals Company. In this study, FGD was used to get an overview of particular issues such as the existing problems associated with the use of aquaculture drugs. A total of 10 FGD sessions was conducted where each group size of FGD was 21.5 people. FGD session was held in front of hatchery or gher, representative offices, chemical sellers shop and so on.

\subsubsection{Crosschecked interviews}

After collecting the data through questionnaire interviews and FGD, crosscheck interviews were conducted with Upazila Fisheries Officer, Assistant Fisheries Officer, relevant NGO workers, chemical seller and medical representative of Pharmaceuticals Company at their offices.

\subsubsection{Secondary data collection}

Secondary source of information consist of published material such as journals (for example, Al-Asif et al., 2021), textbooks, university thesis (up to post-graduate level), newspaper and other sources. Moreover, appropriate government and non-government organizations reports were also taken into consideration for gathering information. The existing problems associated with the use of aquaculture drugs were also collected from the secondary source.

\subsection{Data processing and analysis}

The data was analyzed using tabular and descriptive statistical techniques. The summary tables were prepared in accordance to the objective of the study. Data collected from various sources was entered into a data base system using Microsoft office Software. The processed data were transferred to a master sheet from which classified tables were prepared revealing the findings of the study. At each stage of survey data sheets were compared with original data sheets to ensure the accuracy of data entered.

\section{Results}

\subsection{Aqua drugs and chemicals producing companies}

The current study found, a total 33 companies were either producing or marketing aqua medicines, drugs and chemicals (AMDC) products targeting freshwater aquaculture in South-Eastern part of Bangladesh. ACI Animal Health Ltd., Square Pharmaceuticals Ltd., Acme Laboratories, Novartis Animal Health Ltd., Eon Animal Health., Organic Pharmaceuticals Ltd., Renata Ltd., CP Company, Rals Agro Ltd., and many other companies were noticed that produced, imported and marketed different AMDC products for freshwater aquaculture in that regions (Table 1). The most of the imported products were imported from countries such as India, USA, Thailand, Taiwan, Indonesia, Malaysia and Spain.

Table 1. AMDC producing, importing and marketing companies available in the South-Eastern part of Bangladesh.

\begin{tabular}{ll}
\hline & Name of companies \\
\hline Eon Animal Health & VnF Agro Ltd. \\
Square Agrovet Division & One Pharma Ltd. \\
Novartis Pharmaceuticals Ltd. & NAAFCO Pharma Ltd. \\
ACI Animal Health & Bismillah Enterprise Ltd. \\
SK+F Animal Health. & NutriHealth Ltd. \\
The ACME Laboratories Ltd. & Advanced Agrotech (BD) Ltd. \\
Nature Care Ltd. & Chemical Seller \\
Fishtech (BD) Limited & Promim Agro vet Industries \\
Penta Agrovet Ltd. & PRAN Agro Business Ltd. \\
Organic Pharmaceuticals Ltd. & Univet Ltd. \\
First Care Agro Ltd. & Save and Safe Agroscience Bangladesh \\
Lion Overseas Trading Company & Verno Bio-Splutions Ltd. \\
Catapol Bioscience Ltd. & Agrosol Bangladesh Company
\end{tabular}


Avon Animal Health

Navana Limited

Renata Animal Health

S.S.S Agro Care Ltd.
Uttara Tread bd.

Century Agro Ltd.

Ultimate (BD) Ltd.

\subsection{Categorization of AMDC products}

According to the findings of the current study, the total number of AMDC goods accessible in the study region totaled 330 items, comprising highest number of growth promoters (GP) (total 59 items; 17.88\%), followed by disinfectant and disease treatment (DD) (total 49 items; $14.85 \%$ ), water quality and pond management (WQPM) (total 47 items; 14.24\%), oxygen supply (OS) (total 36 items; 14.24\%), toxic gas reducer (TGR) (total 30 items; $10.91 \%$ ) and rest of the products were found to be less than 30 items and $10 \%$ of total numbers. However, We found antibiotics contributes 19 items and $5.76 \%$ of the total AMDC available in the study area (Figure 2).

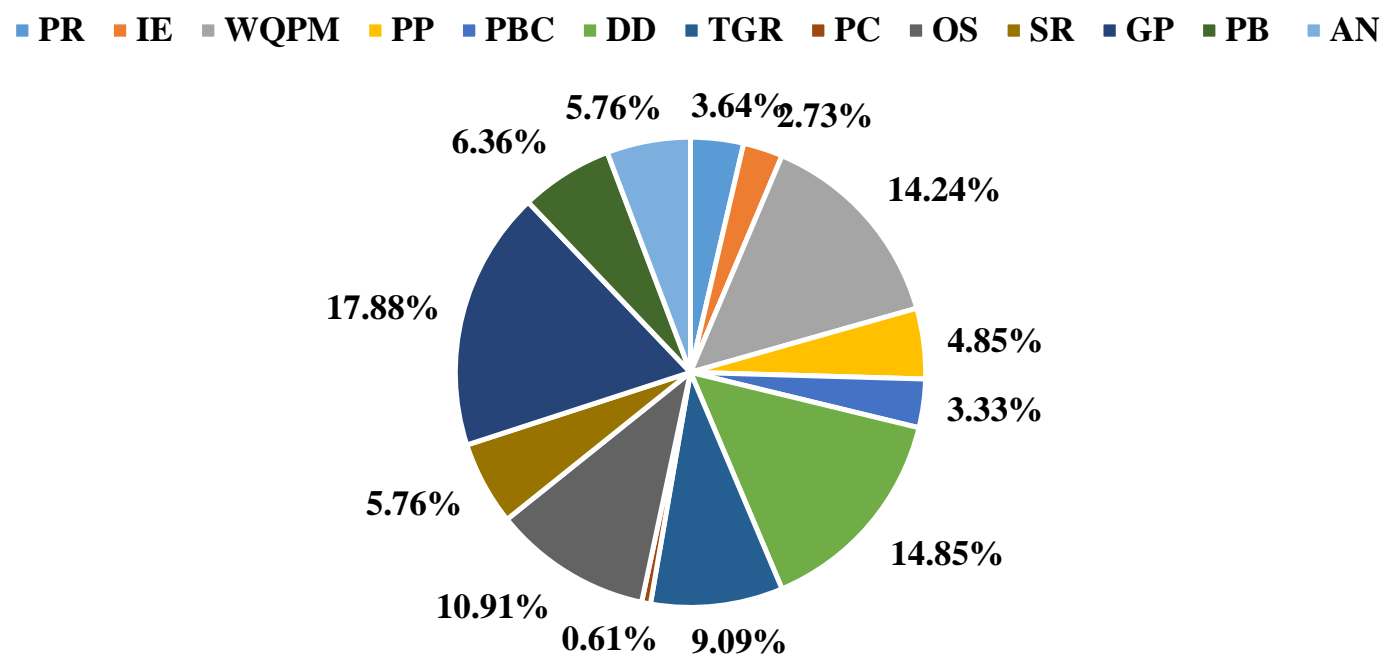

Figure 2. Categorization of AMDC products available in south-eastern part of Bangladesh (Predator removal=PR; insecticides and ectoparasiticides=IE; water quality and pond management=WQPM; plankton producer=PP; plankton bloom cleaner=PBC; disinfectant and disease treatmen=DD; toxic gas reducer=TGR; $\mathbf{p H}$ controller=PC; oxygen supply=OS; stress reducer=SR; growth promoter=GP; probiotics $=\mathrm{PB}$ and antibiotics $=\mathrm{AN})$.

\subsubsection{AMDC used as predator removal}

Farmers use rotenone powder to remove predator and unwanted fish. Rotenone is provided by different pharmaceutical company. The dose of Rotenone depends on water depth and company's products. Following rotenone powder was found in the study (Table 2). Mainly Rota Plus, Napko Glod, Hunter, Phostoxine, Aquanone were used to remove predator and unwanted fish.

Table 2. AMDC used for removal of predator from aquaculture setup.

\begin{tabular}{|c|c|c|c|}
\hline Trade Name & Active Ingredients & Doses/ 3-6 feet water & Sources \\
\hline Aquroted gold & Rotenone $9 \%$ & $35 \mathrm{~g}$ decimal-1 ft-1 depth & ACI Animal Health \\
\hline T Seed Cake & Saponin $15-16 \%$ & $800 \mathrm{~g}$ decimal- $1 \mathrm{ft}-1$ & ACI Animal Health \\
\hline Rota Plus & Rotenone 9\% & $30 \mathrm{~g}$ decimal-1 ft-1 depth & ACI Animal Health \\
\hline Rotenil & Rotenone $9 \%$ & $1 \mathrm{~kg} / 100 \mathrm{dec}$ (depth $4-5 \mathrm{ft})$. & SK+F Pharmaceuticals Ltd. \\
\hline Napko Glod & Rotenone $9 \%$ & $20 \mathrm{~g}$ decimal-1 ft-1 depth & NAAFCO Pharma Ltd. \\
\hline Hunter & Rotenone $9 \%$ & $18 \mathrm{~g}$ decimal- $1 \mathrm{ft}-1$ depth & Eon Animal Health \\
\hline Aquanone & Rotenone $9 \%$ & $5-7 \mathrm{~kg} / 100 \mathrm{dec}$ & Square AgroVet Division \\
\hline Phostoxine & Almmonim phosphide & 2-3 Tablets decimal-1 & Fishtech (BD) Limited \\
\hline Raj-fume $56 \%$ & Almmonim phosphide & 2 Tablets decimal- 1 & Aquaculture International Co. BD \\
\hline Aquanone & Rotenone $9 \%$ & $5-7 \mathrm{~kg} / 100 \mathrm{dec}$ & Square AgroVet Division \\
\hline Fewmitix $56 \%$ & Almmonium Fosfide & 5 tablet/ decimal/ depth 5 ft.) & One Pharm Animal Health \\
\hline Rotenone & Rotenone $9 \%$ & $6-7 \mathrm{~kg} / 100 \mathrm{dec}$ & First Care Agro Ltd. \\
\hline
\end{tabular}




\subsubsection{AMDC used as insecticides and ectoparasiticides}

Wide ranges of chemicals or formulations are being used by the fish farmers for the treatment of parasitic infestations caused by fish louse (Argulus sp.), gill flukes (Dactylogyrus sp.), Myxobolllus sp., ich (Ichthyophtherius sp.) and gill maggot (Ergasillus sp.) (Table 3).

Table 3. AMDC use for controlling insects and ecto-parasites.

\begin{tabular}{llll}
\hline Trade Name & Active Ingredients & Doses $/ 3-6$ feet water & Sources \\
\hline Argulex & Trichlorofon-40\% & $12-13 \mathrm{ml} / \mathrm{dec} / 3 \mathrm{ft} \mathrm{depth}$ & Eon Animal Health \\
\hline Sumithion & & $5-8 \mathrm{ml} / \mathrm{dec} / 3 \mathrm{ft}$ depth & Setu Corporation Ltd. \\
\hline Engreb & Cypermethrine $10 \%$ & $7 \mathrm{ml} / 33 \mathrm{dec} / \mathrm{ft} \mathrm{depth}$ & Eon Animal Health \\
\hline Paratics & Sumithione $10 \%$ & $100 \mathrm{ml} / 100 \mathrm{dec}, 3 \mathrm{ft}$ depth & Advanced Agrotech (BD) Ltd. \\
\hline Acemec 1\% Oral Solution & Iberrmethrine & $300 \mathrm{ml} / 100 \mathrm{dec}, 5 \mathrm{ft}$ depth & ACI Animal Health \\
\hline Deletix & Deltametrin- $1.75 \%$ & $50 \mathrm{ml} / 100 \mathrm{dec}, 4 \mathrm{ft}$ depth & Fishtech $(\mathrm{BD})$ Limited \\
\hline Deltacin & Deltametrin- $1.75 \%$ & $50 \mathrm{ml} / 100 \mathrm{dec}, 4 \mathrm{ft}$ depth & $\begin{array}{l}\text { Save and Safe Agroscience } \\
\text { Bangladesh }\end{array}$ \\
\hline Terminate & & & Ultimate (bd) Ltd. \\
\hline
\end{tabular}

\subsubsection{Water quality and pond management}

Pond preparation is critical in order to increase the productivity of the whole system. Again, maintaining optimal water quality is very important in determining the success or failure of fish production to a significant degree. This includes $\mathrm{pH}$, total alkalinity, total hardness, dissolved oxygen (DO), ammonia, and nitrite-nitrate concentrations, among other things. A wide range of chemicals, including Mega Zeo plus Acme's Zeolite, Matrix, Pond Gurd, Aqua Lime, Bio Aqua, Geotox, and others, were frequently employed in the pond preparation process and for the maintenance of optimal water quality in the survey area (Table 4).

Table 4. AMDC use for pond preparation and water quality management.

\begin{tabular}{|c|c|c|c|}
\hline Trade Name & Active Ingredients & Doses/ 3-6 feet water & Sources \\
\hline JV Zeolite & $\begin{array}{l}\mathrm{SiO}_{2}, \mathrm{Al}_{2} \mathrm{O}_{3}, \mathrm{Fe}_{2} \mathrm{O}_{3}, \mathrm{CaO}, \mathrm{MgO}, \mathrm{Na}_{2} \mathrm{O}, \\
\mathrm{K}_{2} \mathrm{O}, \mathrm{Mn}, \mathrm{P}\end{array}$ & $5-7 \mathrm{~kg} / 33 \mathrm{dec}$ & Eon Animal Health \\
\hline Matrix & $\mathrm{SiO}_{2}, \mathrm{Al}_{2} \mathrm{O}_{3}, \mathrm{Fe}_{2} \mathrm{O}_{3}, \mathrm{CaO}$ & $6-10 \mathrm{~kg} / 100 \mathrm{dec}$ & Eon Animal Health \\
\hline Super Zeolite & $\mathrm{SiO}_{2}, \mathrm{Al}_{2} \mathrm{O}_{3}, \mathrm{Fe}_{2} \mathrm{O}_{3}, \mathrm{CaO}, \mathrm{MgO}, \mathrm{LoI}, \mathrm{K}_{2} \mathrm{O}$ & $20-30 \mathrm{~kg} / 100 \mathrm{dec}$ & Avon Animal Health \\
\hline Raw Lime & $\mathrm{CaCO}_{3}, \mathrm{Ca}(\mathrm{OH})_{2}$ & $1-2 \mathrm{~kg} / \mathrm{dec}$ & Chemical Seller \\
\hline Mega Zeo Plus & $\mathrm{SiO}_{2}, \mathrm{Al}_{2} \mathrm{O}_{3}, \mathrm{Fe}_{2} \mathrm{O}_{3}, \mathrm{CaO}, \mathrm{MgO}, \mathrm{Na} 2 \mathrm{O}$ & $20-25 \mathrm{~kg} / 100 \mathrm{dec}$ & ACI Animal Health \\
\hline Mega Zeo Gold & $\mathrm{SiO}_{2}, \mathrm{Al}_{2} \mathrm{O}_{3}, \mathrm{Fe}_{2} \mathrm{O}_{3}, \mathrm{CaO}, \mathrm{MgO}, \mathrm{Na}_{2} \mathrm{O}+\mathrm{O}_{2}$ & $20 \mathrm{~kg} / 100 \mathrm{dec}$ & ACI Animal Health \\
\hline Zeoren & Aluminum sodium silicate- $75 \%$ & $20-30 / 100 \mathrm{dec}$ & Renata Animal Health \\
\hline Zeo Prime & $\mathrm{SiO}_{2}, \mathrm{Al}_{2} \mathrm{O}_{3}, \mathrm{Fe}_{2} \mathrm{O}_{3}, \mathrm{CaO}, \mathrm{MgO}, \mathrm{LoI}, \mathrm{K}_{2} \mathrm{O}$ & $20-24 \mathrm{~kg} / 100 \mathrm{dec}$ & SK+F Animal Health \\
\hline Quality Zeolite & $\mathrm{SiO}_{2}, \mathrm{Al}_{2} \mathrm{O}_{3}, \mathrm{Fe}_{2} \mathrm{O}_{3} \mathrm{CaO}, \mathrm{MgO}$ & $20-25 \mathrm{~kg} / 100 \mathrm{dec}$ & Quality Fish Feed Ltd. \\
\hline Aalo Zeolite & $\begin{array}{l}\mathrm{SiO}_{2}, \mathrm{Al}_{2} \mathrm{O}_{3}, \mathrm{Fe}_{2} \mathrm{O}_{3} \mathrm{CaO}, \quad \mathrm{MgO}, \mathrm{TiO}_{2}, \\
\mathrm{MnO}_{2}, \mathrm{~K}_{2} \mathrm{O}, \mathrm{Fe}_{2} \mathrm{O}_{3}, \mathrm{pH}\end{array}$ & $15-20 \mathrm{~kg} / 100 \mathrm{dec}$ & PRAN Agro Business Ltd. \\
\hline Pure Lime & $\mathrm{CaCO}_{3}$ & $1 \mathrm{~kg} / \mathrm{dec}$ & PRAN Agro Business Ltd \\
\hline Vernolite plus & $\begin{array}{l}\mathrm{SiO}_{2}, \mathrm{Al}_{2} \mathrm{O}_{3}, \mathrm{Fe}_{2} \mathrm{O}_{3}, \mathrm{CaO}, \mathrm{MgO}, \mathrm{Na}_{2} \mathrm{O}, \\
\mathrm{K}_{2} \mathrm{O}, \text { C. E. C }=400\end{array}$ & $5-10 \mathrm{~kg} / 100 \mathrm{dec}$ & Verno Bio-Solutions Ltd. \\
\hline Zeo Pel & No label found & & SK+F Pharmaceuticals Ltd. \\
\hline Geo Rich & $\begin{array}{l}\mathrm{SiO}_{2}, \mathrm{Al}_{2} \mathrm{O}_{3}, \mathrm{Fe}_{2} \mathrm{O}_{3}, \mathrm{CaO}, \mathrm{MgO}, \mathrm{Na}_{2} \mathrm{O}, \\
\mathrm{K}_{2} \mathrm{O}\end{array}$ & $15-25 \mathrm{~kg} / 100 \mathrm{dec}$ & Opsonin Agro vet Division \\
\hline Nap Zeo & $\mathrm{SiO}_{2}, \mathrm{Al}_{2} \mathrm{O}_{3}, \mathrm{Fe}_{2} \mathrm{O}_{3}, \mathrm{CaO}, \mathrm{MgO}, \mathrm{Na}_{2} \mathrm{O}$ & $10-16 \mathrm{~kg} / 100 \mathrm{dec}$ & NAAFCO Pharma Ltd. \\
\hline Pond Gurd & $\mathrm{Al}_{2} \mathrm{O}_{3}$, Yucca, Probitics & & ACI Animal Health \\
\hline Pond Life & $\begin{array}{l}\mathrm{SiO}_{2}, \mathrm{Al}_{2} \mathrm{O}_{3}, \mathrm{Fe}_{2} \mathrm{O}_{3}, \mathrm{CaO}, \mathrm{MgO}, \mathrm{Na} 2 \mathrm{O}, \\
\text { Probitics }\end{array}$ & & ACI Animal Health \\
\hline Geotox & $\mathrm{SiO}_{2}, \mathrm{Al}_{2} \mathrm{O}_{3}, \mathrm{Fe}_{2} \mathrm{O}_{3}, \mathrm{CaO}, \mathrm{MgO}, \mathrm{Na}_{2} \mathrm{O}$ & $20-25 \mathrm{~kg} / 100 \mathrm{dec}$ & Novartis Pharmaceuticals Ltd. \\
\hline One Zeolite & $\begin{array}{l}\mathrm{SiO}_{2}, \mathrm{Al}_{2} \mathrm{O}_{3}, \mathrm{Fe}_{2} \mathrm{O}_{3}, \mathrm{CaO}, \mathrm{MgO}, \mathrm{Na}_{2} \mathrm{O}, \\
\mathrm{K}_{2} \mathrm{O}, \mathrm{Mn}_{2} \mathrm{O}, \mathrm{P}_{2} \mathrm{O}_{5}\end{array}$ & $25-30 \mathrm{~kg} / 100 \mathrm{dec}$ & One Pharm Animal Health \\
\hline Aqua magic & No label found & $05-08 \mathrm{~kg} / 100 \mathrm{dec}$ & Fishtech (BD) Limited \\
\hline Aqua-Zeo Plus & $\mathrm{SiO}_{2}, \mathrm{Al}_{2} \mathrm{O}_{3}, \mathrm{Fe}_{2} \mathrm{O}_{3} \mathrm{CaO}, \mathrm{MgO}, \mathrm{Na}_{2} \mathrm{O}, \mathrm{K}_{2} \mathrm{O}$ & $8 \mathrm{~kg} / 33 \mathrm{dec}$ & Advanced Agro Ltd. \\
\hline $\begin{array}{l}\text { Miracol lime } \\
\text { mila }\end{array}$ & No label found & $100 \mathrm{gm} / \mathrm{dec}$ & The ACME Laboratories Ltd. \\
\hline
\end{tabular}




\begin{tabular}{|c|c|c|c|}
\hline Alpha Zeolite & $\mathrm{SiO}_{2}, \mathrm{Al}_{2} \mathrm{O}_{3}, \mathrm{Fe}_{2} \mathrm{O}_{3} \mathrm{CaO}, \mathrm{MgO}, \mathrm{Na}_{2} \mathrm{O}$ & $20-30 \mathrm{~kg} / 100 \mathrm{dec}$ & Biswas Agrovet Limited \\
\hline Acme's Zeolite & $\mathrm{SiO}_{2}, \mathrm{Al}_{2} \mathrm{O}_{3}, \mathrm{Fe}_{2} \mathrm{O}_{3}, \mathrm{CaO}, \mathrm{MgO}, \mathrm{Na}_{2} \mathrm{O}$ & $21 \mathrm{~kg} / 100 \mathrm{dec}$ & The ACME Laboratories Ltd. \\
\hline $\begin{array}{l}\text { Zeo Fresh } \\
\text { Granular }\end{array}$ & $\mathrm{SiO}_{2}, \mathrm{Al}_{2} \mathrm{O}_{3}, \mathrm{Fe}_{2} \mathrm{O}_{3}, \mathrm{CaO}, \mathrm{MgO}, \mathrm{Na}_{2} \mathrm{O}$ & $24 \mathrm{~kg} / 100 \mathrm{dec}$ & Square AgroVet Division \\
\hline Aqua Lime & $\mathrm{CaO}$ & $250-500 \mathrm{gm} / \mathrm{dec}$ & ACI Animal Health \\
\hline Bio-tuff & $\begin{array}{l}\mathrm{SiO}_{2}, \mathrm{Al}_{2} \mathrm{O}_{3}, \mathrm{Fe}_{2} \mathrm{O}_{3}, \mathrm{CaO}, \mathrm{MgO}, \mathrm{Na}_{2} \mathrm{O}, \\
\mathrm{K}_{2} \mathrm{O}, \mathrm{TiO}\end{array}$ & $15-20 \mathrm{~kg} / 100 \mathrm{dec}$ & Organic Pharmaceuticals Ltd. \\
\hline Aquazet & $\begin{array}{l}\mathrm{SiO}_{2}, \mathrm{Al}_{2} \mathrm{O}_{3}, \mathrm{Fe}_{2} \mathrm{O}_{3}, \mathrm{CaO}, \mathrm{MgO}, \mathrm{Na}_{2} \mathrm{O}, \\
\mathrm{K}_{2} \mathrm{O} \mathrm{Ti}_{2} \mathrm{O} \text {, LoI }\end{array}$ & $20-30 \mathrm{~kg} / 100 \mathrm{dec}$ & $\begin{array}{l}\text { Lion Overseas Trading } \\
\text { Company }\end{array}$ \\
\hline Zeonex & $\mathrm{SiO}_{2}, \mathrm{Al}_{2} \mathrm{O}_{3}, \mathrm{Fe}_{2} \mathrm{O}_{3}, \mathrm{CaO}, \mathrm{MgO}, \mathrm{Na}_{2} \mathrm{O}$ & $20-30 \mathrm{~kg} / 100 \mathrm{dec}$ & Anex vet (pvt.) Ltd. \\
\hline Fish Grow & $\mathrm{S}, \mathrm{Co}, \mathrm{Mg}, \mathrm{K}, \mathrm{N}, \mathrm{P}, \mathrm{Ca}$ & $400 \mathrm{ml} / 100 \mathrm{dec}$ & Bismillah Enterprise Ltd. \\
\hline Bis Zeolite & $\mathrm{SiO}_{2}, \mathrm{Al}_{2} \mathrm{O}_{3}, \mathrm{Fe}_{2} \mathrm{O}_{3}, \mathrm{CaO}, \mathrm{MgO}, \mathrm{Na}_{2} \mathrm{O}$ & $20-30 \mathrm{~kg} / 100 \mathrm{dec}$ & Avon Animal Health \\
\hline Zeolite Plus & $\mathrm{SiO}_{2}, \mathrm{Al}_{2} \mathrm{O}_{3}, \mathrm{Fe}_{2} \mathrm{O}_{3}, \mathrm{CaO}, \mathrm{MgO}, \mathrm{Na}_{2} \mathrm{O}$ & $20-30 \mathrm{~kg} / 100 \mathrm{dec}$ & Penta Agrovet Ltd. \\
\hline Green Zeolite & $\begin{array}{l}\mathrm{SiO}_{2}, \mathrm{Al}_{2} \mathrm{O}_{3}, \mathrm{Fe}_{2} \mathrm{O}_{3}, \mathrm{CaO}, \mathrm{MgO}, \mathrm{Na}_{2} \mathrm{O}, \\
\mathrm{K}_{2} \mathrm{O}, \mathrm{TiO}_{2}\end{array}$ & $20-25 \mathrm{~kg} / 100 \mathrm{dec}$ & Organic Pharmaceuticals Ltd. \\
\hline Zeocare & $\mathrm{SiO}_{2}, \mathrm{Al}_{2} \mathrm{O}_{3}, \mathrm{Fe}_{2} \mathrm{O}_{3}, \mathrm{CaO}, \mathrm{MgO}, \mathrm{Na}_{2} \mathrm{O}$ & $20-22 \mathrm{~kg} / 100 \mathrm{dec}$ & Nature Care \\
\hline Major Zeolite & $\mathrm{SiO}_{2}, \mathrm{Al}_{2} \mathrm{O}_{3}$ & $30-40 \mathrm{~kg} / 100 \mathrm{dec}$ & Univet Ltd. \\
\hline Pontox Plus & $\mathrm{SiO}_{2}, \mathrm{Al}_{2} \mathrm{O}_{3}, \mathrm{Fe}_{2} \mathrm{O}_{3}, \mathrm{CaO}, \mathrm{MgO}, \mathrm{Na}_{2} \mathrm{O}$ & $15-20 \mathrm{~kg} / 100 \mathrm{dec}$ & Rals Agro Ltd. \\
\hline Well Zeolite & $\mathrm{SiO}_{2}, \mathrm{Al}_{2} \mathrm{O}_{3}, \mathrm{Fe}_{2} \mathrm{O}_{3}, \mathrm{CaO}, \mathrm{MgO}, \mathrm{Na}_{2} \mathrm{O}$ & $18 \mathrm{~kg} / 100 \mathrm{dec}$ & SK+F Pharmaceuticals \\
\hline Soil Cure & $\mathrm{SiO}_{2}, \mathrm{Al}_{2} \mathrm{O}_{3}, \mathrm{Fe}_{2} \mathrm{O}_{3}, \mathrm{CaO}, \mathrm{MgO}, \mathrm{Na}_{2} \mathrm{O}$ & $20-30 \mathrm{~kg} / 100 \mathrm{dec}$ & VnF Agro Ltd. \\
\hline Biotics & $\begin{array}{l}\mathrm{SiO}_{2}, \mathrm{Al}_{2} \mathrm{O}_{3}, \mathrm{Fe}_{2} \mathrm{O}_{3}, \mathrm{CaO}, \mathrm{MgO}, \mathrm{Na}_{2} \mathrm{O} \text {, } \\
\text { Multuenzyme, Yeast, }\end{array}$ & $7-10 \mathrm{~kg} / 100 \mathrm{dec}$ & Advanced Agrotech (BD) Ltd. \\
\hline Zeo Master & $\begin{array}{l}\mathrm{SiO}_{2}, \mathrm{Al}_{2} \mathrm{O}_{3}, \mathrm{Fe}_{2} \mathrm{O}_{3}, \mathrm{CaO}, \mathrm{MgO}, \mathrm{Na}_{2} \mathrm{O}, \\
\mathrm{K} 2 \mathrm{O}, \mathrm{P}, \mathrm{Mn}, \text { C.E.C } 215 \mathrm{mcq} / 100 \mathrm{gm}\end{array}$ & $20-21 \mathrm{~kg} / 100 \mathrm{dec}$ & Nurtihealth Ltd. \\
\hline $\begin{array}{l}\text { Promim Water } \\
\text { Wash }\end{array}$ & $\begin{array}{l}\mathrm{CaCO}_{3}, \mathrm{CuSO}_{4}, \mathrm{Al}_{2}\left(\mathrm{SO}_{4}\right)_{3} 10 \mathrm{H}_{2} \mathrm{O}, \mathrm{K}_{2} \mathrm{SO}_{4}, \\
\mathrm{FeSO}_{4}, \mathrm{C}_{6} \mathrm{H}_{5} \mathrm{COONa}\end{array}$ & $4 \mathrm{~kg} / 33 \mathrm{dec}$ & Promim Agro vet Industries \\
\hline Zeo Magic super & Natural Zeolite, Probiotics, Gas remover & $10 \mathrm{~kg} / 100 \mathrm{dec}$ & First Care Agro Ltd. \\
\hline Zeo First & $\begin{array}{l}\mathrm{SiO}_{2}, \mathrm{Al}_{2} \mathrm{O}_{3}, \mathrm{Fe}_{2} \mathrm{O}_{3}, \mathrm{CaO}, \mathrm{MgO}, \mathrm{Na}_{2} \mathrm{O}, \\
\text { K2O, P, Mn, C.E.C } 214 \mathrm{mcq} / 100 \mathrm{gm}\end{array}$ & $15-20 \mathrm{~kg} / 100 \mathrm{dec}$ & First Care Agro Ltd. \\
\hline Good Earth & No label found & $2-4 \mathrm{~kg} / 100 \mathrm{dec}$ & Catapol Bioscience Ltd. \\
\hline Fish Zeolite & $\begin{array}{l}\mathrm{SiO}_{2}, \mathrm{Al}_{2} \mathrm{O}_{3}, \mathrm{Fe}_{2} \mathrm{O}_{3}, \mathrm{CaO}, \mathrm{MgO}, \mathrm{Na}_{2} \mathrm{O}, \\
\mathrm{K}_{2} \mathrm{O}\end{array}$ & $20-22 \mathrm{~kg} / 100 \mathrm{dec}$ & Uttara Tread bd. \\
\hline Zeo Tiger & $\begin{array}{l}\mathrm{SiO}_{2}, \mathrm{Al}_{2} \mathrm{O}_{3}, \mathrm{Fe}_{2} \mathrm{O}_{3}, \mathrm{CaO}, \mathrm{MgO}, \mathrm{Na}_{2} \mathrm{O}, \\
\mathrm{K}_{2} \mathrm{O}, \mathrm{P}_{2} \mathrm{O}_{5}, \mathrm{TiO}_{2}, \mathrm{MnO}_{2} \text {, LOI, C.E.C. }=80- \\
160 \text { mcq } / 100 \text { gm }\end{array}$ & $10-20 \mathrm{~kg} / 100 \mathrm{dec}$ & Univet Ltd. \\
\hline Zeolite Gold & Zeolite, Yuuka, Probiotics & $1.5-2 \mathrm{~kg} / 100 \mathrm{dec}$ & Uttara Tread bd. \\
\hline
\end{tabular}

\subsubsection{AMDC as plankton producer}

The primary constituent of the aquaculture food web, phytoplankton, is found in abundance in natural waters, but the natural quantity of phytoplankton is insufficient to support desired levels of shrimp and fish production. In addition to increasing the natural fertility of ponds, fertilizers also help to improve crop yields. Many aquaculture farmers, on the other hand, have shifted to feed-based aquaculture in order to boost output beyond what is feasible with conventional fertilizers. Different types of chemical were used for growing phytoplankton and Zooplankton in the study area (Table 5).

Table 5. AMDC used for plankton enhancer in the aquacultures setup in the study area.

\begin{tabular}{llll}
\hline Trade name & Active ingredient & Doses/3-6 ft water & Sources \\
\hline Plankton Grow & $\mathrm{N}, \mathrm{P}, \mathrm{K}, \mathrm{Ca}, \mathrm{Mg}$, others & $1.5 \mathrm{~kg} / 33 \mathrm{dec}$ & ACI Animal Health \\
\hline Benthods & $\begin{array}{l}\text { Compost Urea, Vitamin, Mineral, } \\
\text { Ammonium silicate }\end{array}$ & $150 \mathrm{gm} / \mathrm{dec}$. & ACI Animal Health \\
& $\mathrm{N}, \mathrm{P}, \mathrm{K}, \mathrm{Ca}, \mathrm{Mg}$ & $2 \mathrm{~kg} / 100 \mathrm{dec}$ & ACI Animal Health \\
\hline Vita Plakton & Organic Fertilizer & & ACI Animal Health \\
\hline Pond Ferti & $\begin{array}{l}\text { Sea-weed Extract, Enzyme precursors, } \\
\text { Micronutrients }\end{array}$ & Square AgroVet Division \\
\hline Aqua Green G & & \\
\hline Bio Pond & $\begin{array}{l}\text { Vitamin, Mineral, Probiotics and } \\
\text { Prebiotics }\end{array}$ & found recommendation & SK+F Pharmaceuticals Ltd. \\
\hline Aqua cal & Ca-22\% and Sulper-17\% & $5 \mathrm{~kg} / 33 \mathrm{dec}$ & ACI Animal Health \\
\hline Green Food & Dicalcium phosphate, and all mineral & $4-5 \mathrm{~kg} / 100 \mathrm{dec}$ & Ultimate (bd) Ltd. \\
\hline
\end{tabular}




\begin{tabular}{|c|c|c|c|}
\hline & composition & & \\
\hline Aqua Food & $\begin{array}{l}\text { Fulvic acid, minerals, organic } \\
\text { complex, plant growth stimulator }\end{array}$ & $600-700 \mathrm{gm} / 100 \mathrm{dec}$ & Ultimate (bd) Ltd. \\
\hline Well Bloom & Silicon, Plankton Growth promoter & 4 liter/100 dec & First Care Agro Ltd. \\
\hline Greenmix Aqua & $\begin{array}{lll}\mathrm{CaCO}_{3}, & \text { Phosphorous, } & \text { Humus, } \\
\text { Probiotics } & & \end{array}$ & $1-2 \mathrm{~kg} / 100 \mathrm{dec}$ & Advanced Agrotech (BD) Ltd. \\
\hline Live Food & $\begin{array}{ll}\text { Multivitamin, } & \text { Multimineral, } \\
\text { Dicalcium Phosphate } & \end{array}$ & $5-6 \mathrm{~kg} / 100 \mathrm{dec}$ & Advanced Agrotech (BD) Ltd. \\
\hline Nugel & Growth promoter & 3 liter/100 dec & NAAFCO Pharma Ltd. \\
\hline All plankkot- L & Minerals with probiotics & $2.5 \mathrm{ml} / 100 \mathrm{dec}$ & One Pharm Animal Health \\
\hline $\begin{array}{l}\text { Promim Aqua } \\
\text { Vita }\end{array}$ & $\begin{array}{lllll}\mathrm{MgSO}_{4}, \quad \mathrm{Ca} & \left(\mathrm{PO}_{4}\right)_{2}, & \mathrm{CoSO}_{4}, & \mathrm{~S}, & \mathrm{~B} \\
\mathrm{C}_{6} \mathrm{H}_{5} \mathrm{COONa} & \end{array}$ & $12 \mathrm{~kg} / 100 \mathrm{dec}$ & Promim Agro vet Industries \\
\hline $\begin{array}{l}\text { Verno } \text { Bloom } \\
\text { Plus }\end{array}$ & $\begin{array}{l}\text { Essential Macro and Micro Nutrients } \\
\text { with growth promoter }\end{array}$ & $4 \mathrm{~kg} / 100 \mathrm{dec}$ & Verno Bio-Solutions Ltd \\
\hline
\end{tabular}

\subsubsection{AMDC as plankton bloom cleaner}

This rapid growth and dense buildup of algae causes deoxygenation of the water and the production of poisonous chemicals known as phycotoxins, which are detrimental to both aquatic and human life. Different types of AMDC were used for removing or controlling the toxic algae and phytoplankton growth in the study area (Table 6).

Table 6. List of plankton bloom cleaner.

\begin{tabular}{|c|c|c|c|}
\hline Trade name & Active ingredient & Doses/3-6 ft water & Sources \\
\hline No Alage & Chlro-alkali finale urea concentrated- $4 \%$ & 1 liter $/ 100 \mathrm{dec}$ & ACI Animal Health \\
\hline Fytonil & $\begin{array}{l}\text { Copper, EDTA,Copper citrate, Inert } \\
\text { ingradients }\end{array}$ & 3-4 litter/100 dec & Agrosol Bangladesh Company \\
\hline Killmax Plus & Copper-50 gm, Inter Composition & 3-5 liter/acer & $\begin{array}{lll}\text { Save \& } \quad \& \quad \text { Safe } & \text { Agroscience } \\
\text { Bangladesh } & & \\
\end{array}$ \\
\hline Met Alage & $\begin{array}{l}\text { Alimental copper-10\%, Ethylene } \\
\text { Diamin-32\%, Natural Fungicide-58\% }\end{array}$ & 2-4 litter/100 dec & Univet Ltd. \\
\hline Droper & Chlro-alkali finale urea concentrated-9\% & $0.500-1$ liter $/ 100 \mathrm{dec}$ & Univet Ltd. \\
\hline Faito Alage & No label found & 2 liter $/ 100 \mathrm{dec}$ & No label found \\
\hline Kill Alage & No label found & 1 liter $/ 100 \mathrm{dec}$ & No label found \\
\hline Cupper Sulphet & $\mathrm{CuSO}_{4}$ & & Chemical \\
\hline $\begin{array}{l}\text { Promim Algae } \\
\text { Clear plus }\end{array}$ & $\mathrm{CuSo}_{4}, \mathrm{C}_{6} \mathrm{H}_{5} \mathrm{COONa}$, EDTA, BKC & 1liter/100 dec & Promim Agro vet Industries \\
\hline $\begin{array}{l}\text { Promim Aqua } \\
\text { Solution Plus }\end{array}$ & $\begin{array}{l}\mathrm{NaOH}, \mathrm{CuSo}_{4}, \mathrm{C}_{6} \mathrm{H}_{5} \mathrm{COONa}, \text { EDTA, } \\
\mathrm{BKC}\end{array}$ & 3 liter/100 dec & Promim Agro vet Industries \\
\hline Verno Drop & No label found & $100 \mathrm{ml} / 33 \mathrm{dec}$ & Verno Bio-Solutions Ltd \\
\hline
\end{tabular}

\subsubsection{AMDC used as disinfectant and disease treatment}

In aquaculture, a variety of chemicals are available for use as disinfectants and as a measure of better health management. The active components in a wide range of antimicrobial disinfectants or sanitizers typically used for fish health management in the study area. Timsen, pathonit, Virex, Aquakleen, Pathocide, BKC (Benzalkonium chloride), potassium permanganate, copper sulphate, Bactisal, Virusnip, and Polgard plus are some of the regularly used chemical preparations for disease control. Spa can be used to heal diseases as well as encourage growth. BKC is used to control bacterial illness while formalin is used to control protozoan parasite infestation (Table 7). 
Table 7. AMDC used as disinfectant and disease treatment.

\begin{tabular}{|c|c|c|c|}
\hline Trade name & Active ingredients & Doses /3-6 ft water & Sources \\
\hline Timsen & $\begin{array}{l}\text { n-Alkyl dimethyl benzyl } \\
\text { ammonium chloride- } 40 \% \text {, } \\
\text { stabilized urea- } 60 \%\end{array}$ & $\begin{array}{l}20 \mathrm{~g} / 33 \mathrm{dec} . \text { (for } \\
\text { prevention), } 80 \mathrm{~g} / 33 \mathrm{dec} . \\
\text { (for treatment) }\end{array}$ & Eon Animal Health \\
\hline Pathonil & $\begin{array}{l}\text { n-Alkyl dimethyl benzyl } \\
\text { ammonium chloride- } 80 \%\end{array}$ & $200 \mathrm{ml} / 33 \mathrm{dec}$ & ACI Animal Health \\
\hline Acidin & Iodine & & ACI Animal Health \\
\hline Germnil & BKC-50\% + Glutaraldehyde & No recommendation found & NAAFCO Pharma Ltd. \\
\hline Bleaching powder & Clorine & $0.1-1 \mathrm{ppm}$ & Chemical Seller \\
\hline Eon CTC & Efinol & 5-8 gm/liter water & Eon Animal Health \\
\hline Emsen & $\begin{array}{l}\text { n-Alkyl dimethyl benzyl } \\
\text { ammonium chloride }+ \text { stabilized } \\
\text { urea }\end{array}$ & $80 \mathrm{gm} / 33 \mathrm{dec}$ & SK+F Pharmaceuticals Ltd. \\
\hline Aquaxide Plus & $\begin{array}{l}\text { Alkyl dimethyl benzyl } \\
\text { ammonium chloride }+ \\
\text { Glutaraldehyde }\end{array}$ & $500-750 \mathrm{ml} / 100 \mathrm{dec}$ & Advanced Agrotech (BD) Ltd. \\
\hline Virokill Aqua & $\begin{array}{l}\text { Alkyl dimethyl benzyl } \\
\text { ammonium chloride- } 80 \%\end{array}$ & $500-750 \mathrm{ml} / 100 \mathrm{dec}$ & Advanced Agrotech (BD) Ltd \\
\hline Onesol P & $\begin{array}{l}\text { n-Alkyl dimethyl benzyl } \\
\text { ammonium chloride- } 40 \% \text {, } \\
\text { stabilized urea- } 60 \%\end{array}$ & $5 \mathrm{gm} / \mathrm{dec}$ & One Pharm Animal Health \\
\hline Onesol L & $\begin{array}{l}\text { Tetradyile Trimethyle } \\
\text { Ammonium Bromide- } 6.7 \%+ \\
\text { Alkyl dimethyl benzyl } \\
\text { ammonium chloride- } 83 \%\end{array}$ & $5-10 \mathrm{ml} / \mathrm{dec}$ & One Pharm Animal Health \\
\hline $\mathrm{BKC}$ & $\begin{array}{l}\text { n-Alkyl dimethyl benzyl } \\
\text { ammonium chloride- } 80 \%\end{array}$ & $500-600 \mathrm{ml} / 100 \mathrm{dec}$ & VnF Agro Ltd. \\
\hline BKC-800 & Benzal konium chloride- $80 \%$ & $500 \mathrm{ml} / 100 \mathrm{dec}$ & First Care Agro Ltd. \\
\hline Protector Plus & $\begin{array}{l}\text { Alkyl dimethyl benzyl } \\
\text { ammonium chloride }+ \\
\text { Glutaraldehyde }\end{array}$ & $350-500 \mathrm{ml} / 100 \mathrm{dec}$ & Ultimate (bd) Ltd. \\
\hline Topper Aqua & $\begin{array}{l}\text { Alkyl dimethyl benzyl } \\
\text { ammonium chloride- } 80 \%\end{array}$ & $350-500 \mathrm{ml} / 100 \mathrm{dec}$ & Ultimate (bd) Ltd. \\
\hline Mector BKC & $\begin{array}{l}\text { Alkyl dimethyl benzyl } \\
\text { ammonium chloride- } 80 \%+ \\
\text { Acetic acid- } 10 \% \text { Glutaraldehyde } \\
-5 \%\end{array}$ & $300-500 \mathrm{ml} / 100 \mathrm{dec}$ & Univet Ltd. \\
\hline Oxykol & Per acetic acid-90 gm/kg & $250-500 \mathrm{gm} / 100 \mathrm{dec}$ & Univet Ltd. \\
\hline Aqua Guard & $\begin{array}{l}\text { Alkyl dimethyl benzyl } \\
\text { ammonium chloride- } 80 \%+ \\
\text { Teradecyl trimethyl ammonium } \\
\text { bromide- } 6.7 \%\end{array}$ & $300-600 \mathrm{ml} / 100 \mathrm{dec}$ & PRAN Agro Business Ltd \\
\hline Aquasen & $\begin{array}{l}\text { Alkyl dimethyl benzyl } \\
\text { ammonium chloride- } 40 \%+ \\
\text { Alkyl dimethyl benzyl } \\
\text { ammonium chloride- } 60 \%\end{array}$ & $\begin{array}{l}100 \mathrm{gm} / 100 \mathrm{dec} . \text { (for } \\
\text { prevention), } 250 \mathrm{gm} / 33 \\
\text { dec (for treatment) }\end{array}$ & PRAN Agro Business Ltd \\
\hline Superio & Iodofour & $500 \mathrm{ml} / 100 \mathrm{dec}$ & Verno Bio-Splutions Ltd \\
\hline Bromi-5 & Bromine 5\% & $5-10 \mathrm{ml} / \mathrm{dec}$ & VnF Agro Ltd. \\
\hline $\begin{array}{l}\text { Promim Anti- } \\
\text { virus }\end{array}$ & $\begin{array}{l}\text { Alkyl dimethyl benzyl } \\
\text { ammonium chloride + ISO } \\
\text { Propanol Methylenblue } \\
\mathrm{C}_{6} \mathrm{H}_{5} \mathrm{COONa}\end{array}$ & $500 \mathrm{ml} / 33 \mathrm{dec}$ & Promim Agro vet Industries \\
\hline $\begin{array}{l}\text { Promim Aqua } \\
\text { Qripus }\end{array}$ & $\begin{array}{l}\mathrm{CaCo}_{3}, \mathrm{KMnO}_{4}, \mathrm{P}, \mathrm{Mn} \\
\mathrm{C}_{37} \mathrm{H}_{27} \mathrm{~N}_{3} \mathrm{Na}_{2} \mathrm{O}_{9} \mathrm{~S}_{3}, \mathrm{P}, \mathrm{NaCl}, \\
\mathrm{C}_{6} \mathrm{H}_{5} \mathrm{COONa}\end{array}$ & $2 \mathrm{~kg} / 33$ dce & Promim Agro vet Industries \\
\hline Formalin & $38 \%$ Formaldehyde & $1-3 \mathrm{ppm}$ & Chemical Seller \\
\hline Lenocide & $\begin{array}{l}\text { Ankul benzyl dimethyl } \\
\text { ammonium chloride }+ \text { poly- } 2\end{array}$ & $500-1000 \mathrm{ml} / 100 \mathrm{dec}$ & Nature care \\
\hline
\end{tabular}




\begin{tabular}{|c|c|c|c|}
\hline & deoxy-2 amino glucose & & \\
\hline Omicide & $\begin{array}{l}\text { Benzyl ammonium chloride }+ \\
\text { urea }\end{array}$ & $200 \mathrm{ml} / 33 \mathrm{dec}$. & Lion overseas trading company \\
\hline Virex & $\begin{array}{l}\text { Potassium Peroxymono sulphate } \\
50 \%\end{array}$ & $100-200 / 33 \mathrm{dec}$ & ACI Animal Health \\
\hline EDTA & Sodium thiosulphate & $0.1-1 \mathrm{ppm}$ & Chemical seller \\
\hline Water clear 300/L & Sodium thiosulphate & $2-3 \mathrm{~L} / 100 \mathrm{dec}$. & Organic pharmaceuticals Ltd. \\
\hline Aquakleen & $\begin{array}{l}\text { Tetradesail Tri-methyl Amonium } \\
\text { bromid, BKC }\end{array}$ & $0.5-1 \mathrm{~L} / 100 \mathrm{dec}$ & Square AgroVet Division \\
\hline Microbite & $\begin{array}{l}\text { Benzal konium chloride+ } \\
\text { providin Iodine }\end{array}$ & $100-150 \mathrm{ml} / 33 \mathrm{dec}$ & Nutrihealth Ltd. \\
\hline Albez & $\begin{array}{l}\text { Doxycyclin, colistine sulphate }+ \\
\text { vitamin premix }+ \text { mineral }\end{array}$ & No recommendation found & Syngenta pharmaceuticals Ltd \\
\hline $\mathrm{BKC}$ & Benzal konium chloride & $\begin{array}{l}\text { Spread with water, } 0.5 \\
\text { ppm }\end{array}$ & Chemical seller \\
\hline Polgard plus & $\begin{array}{l}\text { 3-Methyl and 4-Methyl two } \\
\text { chain brominated compound }\end{array}$ & $500 \mathrm{ml} / 100 \mathrm{dec}$ & Fishtech (BD) Limited \\
\hline Farmsafe & $\begin{array}{l}\text { Didisyle Dimethyl Ammonium } \\
\text { chloride + Ethylalcohol +Yucca }\end{array}$ & $250-300 \mathrm{ml} / 100 \mathrm{dec}$ & Catapol Bioscience Ltd. \\
\hline Bioxide & $\begin{array}{l}\text { Alkyl dimethyl benzyl } \\
\text { ammonium chloride- } 80 \%+ \\
\text { Glutaraldehyde }-50 \%\end{array}$ & $350-500 \mathrm{ml} / 100 \mathrm{dec}$ & $\begin{array}{l}\text { Save and Safe Agroscience } \\
\text { Bangladesh }\end{array}$ \\
\hline Virocin & $\begin{array}{l}\text { Dichlro Ammonium chloride- } \\
1 \% \text { + Iodine-3\% + Dimethyl blue }\end{array}$ & $200-300 \mathrm{gm} / 100 \mathrm{dec}$ & Agrosol Bangladesh Company \\
\hline Bactisal-80 & $\begin{array}{l}\text { Ankul benzyl dimethyl } \\
\text { ammonium chloride }\end{array}$ & $350 \mathrm{ml} / 100 \mathrm{dec}$ & First Care Agro Ltd. \\
\hline Well Guard & Bromine- $5 \%$ & $500 \mathrm{ml} / 100 \mathrm{dec}$ & First Care Agro Ltd. \\
\hline Lenocide & $\begin{array}{l}\text { Ankul benzyl dimethyl } \\
\text { ammonium chloride }+ \text { poly-2 } \\
\text { deoxy- } 2 \text { amino glucose }\end{array}$ & $500 \mathrm{ml} / 100 \mathrm{dec}$ & Nature care Ltd. \\
\hline Virusnip & $\begin{array}{l}\text { Potassium peroxymonosulphate } \\
50 \% \text {, Sodium } \\
\text { dichloroisocyanurate } 5 \% \text {, } \\
\text { Excipients } 45 \%\end{array}$ & $300-400 \mathrm{~g} / 100 \mathrm{dec}$ & Novartis Animal Health \\
\hline Germclean & $\begin{array}{l}\text { Alkyl dimethyl benzyl } \\
\text { ammonium chloride }\end{array}$ & 1-1.5 litter/100 dec & Uttara Tread bd. \\
\hline Auqa Fair & $\begin{array}{l}\mathrm{C}_{17} \mathrm{H}_{30} \mathrm{CIN}-40 \%, \mathrm{CH}_{3} \mathrm{COON}- \\
10 \%, \mathrm{HCHO}-5 \%, 3 \mathrm{CHO}-5 \% \text {, } \\
\text { OHCCHO-5\% }\end{array}$ & $400-600 \mathrm{gm} / 100 \mathrm{dec}$ & Uttara Tread bd. \\
\hline Potash & $\mathrm{KMnO}_{4}$ & $5-15 \mathrm{mg} / 100 \mathrm{dec}$ & Chemical seller \\
\hline Salt & $\mathrm{NaCl}$ & $500-1000 \mathrm{~g} / 100 \mathrm{dec}$ & Chemical seller \\
\hline Malachite green & $\mathrm{C}_{2} \mathrm{H}_{2} \mathrm{O}_{4}$ & $1 \mathrm{ppm} ; 1 \mathrm{~min} ; \operatorname{dip}$ & Chemical seller \\
\hline Melethion & Active melathion & $500 \mathrm{~g} / 100 \mathrm{dec}$ & Chemical seller \\
\hline Methylene blue & $\mathrm{C}_{10} \mathrm{H}_{18} \mathrm{CIN}_{3} \mathrm{SxH}_{2} \mathrm{O}$ & $\begin{array}{l}\text { 2-3ppm bath for } 1 \mathrm{~h} / 10-20 \\
\mathrm{mg} / \mathrm{L} \text { for } 15 \mathrm{~min} .\end{array}$ & Chemical seller \\
\hline Copper Sulphate & $\mathrm{CuSO}_{4}$ & $15-25 \mathrm{mg}$ decimal & Chemical seller \\
\hline
\end{tabular}

\subsubsection{AMDC used as toxic gas reducer}

Farmers have been observed adding a gas removal agent to their culture ponds in order to remove organic and inorganic wastes that are generating gas. Some of the probiotics utilised in feed included MI Plus, Yuka, Ammonil, Gas check, Aqua Pure Powder, Gasonil, Pond Kleen, Bio-Aqua-50, Gasonex plus, Gas kit, and Gasonex plus plus, among other things (Table 8). 
Table 8. List of available AMDC used as toxic gas reducer in the study area.

\begin{tabular}{|c|c|c|c|}
\hline Trade Name & Active ingredients & Doses/3-6 ft water & Sources \\
\hline MI Plus & $\begin{array}{ll}\text { Bacillus subtillis, } & \text { Bacillus } \\
\text { licheniformis, } & \text { Bacillus } \\
\text { megaterim, Bacillus } & \text { pumilus, } \\
\text { Bacillus amyloliqefaciens }\end{array}$ & $40-50$ tablet/ $100 \mathrm{dec}$ & ACI Animal Health \\
\hline Yuka & $\begin{array}{l}\text { Yucca plant extract, Saponin } \\
\text { Components Glyco components }\end{array}$ & $300 \mathrm{ml} / 100 \mathrm{dec}$ & Opsonin Agrovet Division \\
\hline Bio-Aqua-50 & $\begin{array}{l}\text { Yucca plant extract, Saponin } \\
\text { Components Glyco components }\end{array}$ & $60-70 \mathrm{ml} / 33 \mathrm{dec}$ & Eon Animal Health \\
\hline Bio- Aqua liquid & Yucca plant extract & $200-300 \mathrm{ml} / 100 \mathrm{dec}$ & Nutrihealth Ltd. \\
\hline Faast & $\begin{array}{l}\text { Yucca plant extract, Saponin } \\
\text { Components Glyco }\end{array}$ & $100 \mathrm{gm} / 33 \mathrm{dec}$ & Nutrihealth Ltd. \\
\hline Gaskleen Aqua & $\begin{array}{l}\text { Natural element, } \\
\text { Microorganism, } \\
\text { Enzyme }\end{array}$ & $200-400 \mathrm{gm} / 100 \mathrm{dec}$ & Advanced Agrotech (BD) Ltd \\
\hline Ammonil & $\begin{array}{l}\text { Yucca plant extract, Bacillus } \\
\text { subtillis, candida utilis }\end{array}$ & $100-200 \mathrm{~g} / 100 \mathrm{dec}$ & $\begin{array}{l}\text { Noverties Pharmaceuticals Co. } \\
\text { Ltd. }\end{array}$ \\
\hline Gas stop & Bacillus subtillis $\mathrm{A} 12 \mathrm{O} 3 \mathrm{SiO} 2$ & $500 \mathrm{mg} / 100 \mathrm{dec}, 3$ weeks & $\begin{array}{l}\text { Organic pharmaceuticals Co. } \\
\text { Ltd.(BD) }\end{array}$ \\
\hline Gasonil & Bacillus subtillis & & SK+F Animal Health \\
\hline Pond Kleen & $\begin{array}{l}\text { Yucca plant extract, , Saponin } \\
\text { and Glyco components }\end{array}$ & $300 \mathrm{ml} / 100 \mathrm{dec}$ & ACI Animal Health \\
\hline ACI Yucca Plus & $\begin{array}{l}\text { Yucca plant extract, Bacillus } \\
\text { subtillis, Rhodoseudomonas }\end{array}$ & $300 \mathrm{ml} / 100 \mathrm{dec}$ & ACI Animal Health \\
\hline Victor Aqua & Yucca plant extract & $300-400 \mathrm{gm} / 100 \mathrm{dec}$ & Ultimate (bd) Ltd. \\
\hline Gass free aqua & $\begin{array}{l}\text { Yucca plant extract, Saponin and } \\
\text { Glyco components }\end{array}$ & $0.500-1 \mathrm{~kg} / 100 \mathrm{dec}$ & Renata Animal Health \\
\hline Ammorid & $\begin{array}{l}\text { Nitrifying and Denitrifying } \\
\text { Bacteria }\end{array}$ & $0.500-1$ liter/ $100 \mathrm{dec}$ & Renata Animal Health \\
\hline First Yucca & Yucca plant extract & $200-300 \mathrm{ml} / 100 \mathrm{dec}$ & First Care Agro Ltd. \\
\hline First Pro Yucca & Yucca plant extract, Probiotics & $175-200 \mathrm{gm} / 100 \mathrm{dec}$ & First Care Agro Ltd. \\
\hline Bio Cure & Yucca plant extract, Probiotics & $10-12 \mathrm{~kg} / 100 \mathrm{dec}$ & First Care Agro Ltd. \\
\hline Ammosol Liquid & $\begin{array}{l}\text { Natura Yucca plant extract l } \\
\text { Biochemical compounds }\end{array}$ & $200-400 \mathrm{ml} / 100 \mathrm{dec}$ & $\begin{array}{l}\text { Save and Safe Agroscience } \\
\text { Bangladesh }\end{array}$ \\
\hline Gas Killer & $\begin{array}{l}\text { Yucca plant extract with } \\
\text { probiotics }\end{array}$ & $200-400 / 100 \mathrm{dec}$ & PRAN Agro Business Ltd \\
\hline Gastrap & $\begin{array}{l}\text { Lactic acid Bacillus sp. Bacillus } \\
\text { subtillis Cellulase, Hemicellulase, } \\
\text { amylase }\end{array}$ & $200 \mathrm{mg} / 100 \mathrm{dec}$ & Square Agrovet Division \\
\hline Biomax Power & $\begin{array}{l}\text { Maximum consortium } \\
\begin{array}{l}\text { probiotics bio-fixed on } \\
\text { calcareous matrix }\end{array}\end{array}$ & $4-5 \mathrm{~kg} / 100 \mathrm{dec}$ & Square Agrovet Division \\
\hline Aqua Pure Powder & $\begin{array}{l}\text { Hydrate sodium alumino silicate } \\
\text { with natural adsorbing and } \\
\text { deodorizing agent, Highest CEC }\end{array}$ & $8-10 \mathrm{~kg} / 100 \mathrm{dec}$ & Square Agrovet Division \\
\hline $\begin{array}{l}\text { AMOVER } \\
\text { Remover }\end{array}$ & $\begin{array}{lcr}\begin{array}{l}\text { Essential } \\
\text { Enzyme, }\end{array} \text { Nitrogen } & \text { Yeast, } \\
\text { catalyst, Oxygen } & \text { Factor, }\end{array}$ & $300-400 \mathrm{gm} / 100 \mathrm{dec}$ & VnF Agro Ltd. \\
\hline Aqua Magic & $\begin{array}{l}\text { Azotabactor chorococcum, } \\
\text { Bacillus subtillis, candida utilis }\end{array}$ & $400 \mathrm{~g} / 100 \mathrm{dec}$ & Fishtech (BD) Limited \\
\hline Pond D tox & Pracoccus pantotrophus & $4 \mathrm{ppm}$ & Fishtech (BD) Limited \\
\hline Gas Check Plus & Tetra acetyl ethylene diamin & $200 \mathrm{~g} / 100 \mathrm{dec}$ & First Care Agro Ltd. \\
\hline Gas kit & & $200-300 \mathrm{~g} / 100 \mathrm{dec}$ & Catapol Bioscience ltd. \\
\hline Gasonex plus & Na-lorile ether sulphate & $200-400 \mathrm{mg} / \mathrm{kg}$, Zeolite & Fishtech (BD) Limited \\
\hline Gas Clean & Probiotics and enzyme & $200-300 \mathrm{gm} / \mathrm{acer}$ & Uttara Tread bd. \\
\hline Metox_GR Pro & $\begin{array}{l}\text { Yucca plant extract, Probiotics, } \\
\text { enzyme }\end{array}$ & $200 \mathrm{gm} / 100 \mathrm{dec}$ & Univet Ltd. \\
\hline
\end{tabular}




\subsubsection{AMDC as $\mathrm{pH}$ controller}

The $\mathrm{pH}$ of freshwater environments may vary significantly across daily and seasonal timescales, and most freshwater species have evolved to withstand a rather wide $\mathrm{pH}$ range. Animals, on the other hand, can get stressed or perish when subjected to $\mathrm{pH}$ extremes or fast $\mathrm{pH}$ shifts, even if the change occurs within a $\mathrm{pH}$ range that is typically tolerated. We found two $\mathrm{pH}$ controller products were available in the market of the south eastern Bangladesh (Table 9).

Table 9. The list of AMDC used as pH controller.

\begin{tabular}{llll}
\hline Trade name & Active ingredient & Doses/3-6 ft water & Sources \\
\hline $\mathrm{pH}^{-\mathrm{R}}$ & Organic Acid-15\%, & $\mathrm{pH}: 8-9$, used: 6-8 kg/ $100 \mathrm{dec} ;$ & Univet Ltd. \\
& Gypsum-25\%, Aluminum & $\mathrm{pH}:$ 9-9.5, used: $8-10 \mathrm{~kg} / 100 \mathrm{dec} ;$ & \\
& Silicate-60\% & $\mathrm{pH}:$ above-9.5, used: $10-15 \mathrm{~kg} / 100 \mathrm{dec}$ & \\
\hline Aqua Balance & Sodium humate, & $1 \mathrm{~kg} / 100 \mathrm{dec}$ & Ultimate (bd) Ltd. \\
& $\begin{array}{l}\text { Polymerization aluminum } \\
\text { potassium sulfate, enzyme }\end{array}$ & & \\
& & &
\end{tabular}

\subsubsection{AMDC used for oxygen supply}

To boost the amount of dissolved oxygen in an aquaculture pond, many types of chemicals were applied in the farms of the study area. The most important active constituents in those chemicals are oxidizing agents such as hydrogen peroxide and sodium carbonates (Table 10).

Table 10. AMDC list of chemicals used for oxygen supply.

\begin{tabular}{|c|c|c|c|}
\hline Trade name & Active ingredient & Doses/3-6 ft water & Sources \\
\hline Oxymax & $\mathrm{H}_{2} \mathrm{O}_{2} 10 \%$ & $\begin{array}{l}250-500 \mathrm{gm} / 100 \mathrm{dec} \text { (1 } \mathrm{m} \text { deep water } \\
\text { body) }\end{array}$ & Eon Animal Health \\
\hline Aci-OX & carbonate, & $\begin{array}{l}\text { General dose } 300-400 \mathrm{gm} / 100 \mathrm{dec} \text {. } \\
\text { In case of high deficiency } 500-700 \\
\mathrm{gm} / 100 \mathrm{dec}\end{array}$ & ACI Animal Health \\
\hline Bio-OX & Sodium carbonate, $\mathrm{H}_{2} \mathrm{O}_{2}$ & $\begin{array}{l}\text { General dose } 300-400 \mathrm{gm} / 100 \mathrm{dec} \text {. } \\
\text { In case of high deficiency } 500-700 \\
\mathrm{gm} / 100 \mathrm{dec}\end{array}$ & ACI Animal Health \\
\hline Oxy more & $\begin{array}{l}\text { Sodium carbonate per- } \\
\text { oxyhydrate }\end{array}$ & $\begin{array}{l}\text { General dose } 250-500 \mathrm{gm} / 100 \mathrm{dec} \text {. } \\
\text { In case of high deficiency } 750-1000 \\
\mathrm{gm} / 100 \mathrm{dec}\end{array}$ & SK+F Pharmaceuticals Ltd. \\
\hline Oxy top & Sodium Per carbonate & $250-500 \mathrm{gm} / 100 \mathrm{dec}$ & Nutrihealth Ltd. \\
\hline Han-oxy & $\begin{array}{l}\text { Sodium Per carbonate- } \\
14.5 \%\end{array}$ & $\begin{array}{l}\text { General dose } 250-500 \mathrm{gm} / 100 \mathrm{dec} \text {. } \\
\text { In case of high deficiency } 750-1000 \\
\mathrm{gm} / 100 \mathrm{dec}\end{array}$ & Ultimate (bd) Ltd. \\
\hline First Oxy & Sodium Per carbonate & $500-700 \mathrm{gm} / 100 \mathrm{dec}$ & First Care Agro Ltd. \\
\hline Oxy Aqua & Sodium Per carbonate & $\begin{array}{l}\text { General dose } 500-600 \mathrm{gm} / 100 \mathrm{dec} \text {. } \\
\text { In case of high deficiency } 1000-1200 \\
\mathrm{gm} / 100 \mathrm{dec}\end{array}$ & PRAN Agro Business Ltd \\
\hline Verno Ox & Sodium per carbonate & $5001000 \mathrm{gm} / 100 \mathrm{dec}$ & Verno Bio-Solutions Ltd \\
\hline Oxy Sos & $\begin{array}{l}\text { Sodium per carbonate } \\
\text { Peroxide }\end{array}$ & $300-500 \mathrm{gm} / 100 \mathrm{dec}$ & Advanced Agrotech (BD) Ltd \\
\hline Oxy Rich & Sodium per carbonate & $\begin{array}{l}\text { General dose } 500 \mathrm{gm} / 100 \mathrm{dec} . \mathrm{In} \\
\text { case of high deficiency } 1000 \mathrm{gm} / 100 \\
\text { dec }\end{array}$ & Opsonin Agrovet Division \\
\hline Oxyren & Sodium per carbonate & $1 \mathrm{~kg} / 100 \mathrm{dec}$ & Renata Animal Health \\
\hline $\mathrm{O}_{2}$ marine & $\mathrm{H}_{2} \mathrm{O}_{2} 10 \%$ & $66-90$ tablet/33 dec. & Organic pharmaceuticals ltd. \\
\hline O-plus & $\begin{array}{ll}\mathrm{O} 2 & \text { promoter } \\
\left(\mathrm{H}_{2} \mathrm{O}_{2} / \mathrm{Ca} 2 \mathrm{O} 2\right) & \\
\end{array}$ & $500 \mathrm{gm} / 100 \mathrm{dec}$ & Nature care Ltd. \\
\hline Oxy gold & Sodium percarbonate & $250 \mathrm{~g} / 100 \mathrm{dec}$ & Fishtech (BD) Limited \\
\hline Oxy-plus & $\begin{array}{l}\mathrm{O} 2 \text { promoter } \\
\left.\mathrm{H}_{2} \mathrm{O}_{2} / \mathrm{Ca} 2 \mathrm{O} 2\right)\end{array}$ & $500 \mathrm{gm} / 100 \mathrm{dec}$ & Penta Agrovet ltd. \\
\hline Oxylife & Sodium carbonate $13 \%$ & $400 \mathrm{~g} / 100 \mathrm{dec}$ & Square AgroVet Division \\
\hline
\end{tabular}




\begin{tabular}{|c|c|c|c|}
\hline $\begin{array}{l}\text { Quick } \\
\text { oxygen }\end{array}$ & $\begin{array}{l}\text { Sodium percarbonate }+ \\
\text { free oxygen }\end{array}$ & $\begin{array}{l}\text { In case of high deficiency } 500 \mathrm{gm} / \\
100 \mathrm{dec} \text { in same water body }\end{array}$ & Organic pharmaceuticals Ltd. \\
\hline Oxy-A & Sodium percarbonate & $\begin{array}{l}\text { General dose } 300-400 \mathrm{gm} / 100 \mathrm{dec} . \mathrm{In} \\
\text { case of high deficiency } 500-700 \mathrm{gm} / \\
100 \mathrm{dec}\end{array}$ & The Acme Laboratories Ltd. \\
\hline Oxy flow & $\mathrm{H}_{2} \mathrm{O}_{2} 10 \%$ & $\begin{array}{l}\text { General dose } 250-350 \mathrm{gm} / 100 \mathrm{dec} \text {. In } \\
\text { case of high deficiency } 500 \mathrm{gm} / 100 \\
\text { dec in same water body }\end{array}$ & Novartis Pharmaceuticals Ltd. \\
\hline Oxygen plus & $\begin{array}{l}\mathrm{O} 2 \quad \text { promoter } \\
(\mathrm{H} 2 \mathrm{O} 2 / \mathrm{Ca} 2 \mathrm{O} 2)\end{array}$ & $\begin{array}{l}\text { General dose } 250-500 \mathrm{gm} / 100 \mathrm{dec} . \mathrm{In} \\
\text { case of high deficiency } 750-1000 \mathrm{gm} / \\
100 \mathrm{dec}\end{array}$ & Avon Animal Health \\
\hline Miracle $\mathrm{O}_{2}$ & $\begin{array}{l}\text { Sodium Percarbonate- } \\
13.5 \%\end{array}$ & $\begin{array}{l}\text { General dose } 200-250 \mathrm{gm} / 100 \mathrm{dec} . \mathrm{In} \\
\text { case of high deficiency } 400-500 \mathrm{gm} / \\
100 \mathrm{dec}\end{array}$ & One Pharm Animal Health \\
\hline V-Oxy TAB & $\begin{array}{l}\text { Sodium } \quad \text { carbonate } \\
\text { peroxide }\end{array}$ & $\begin{array}{l}\text { General dose } 500-700 \mathrm{gm} / 100 \mathrm{dec} . \mathrm{In} \\
\text { case of high deficiency } 1-1.2 \mathrm{~kg} / 100 \\
\text { dec }\end{array}$ & VnF Agro Ltd. \\
\hline Oxymix & $\begin{array}{l}\text { Sodium } \\
\text { peroxid-14\% }\end{array}$ & $\begin{array}{l}\text { General dose } 250-500 \mathrm{gm} / 100 \mathrm{dec} \text {. In } \\
\text { case of high deficiency } 750-1 \mathrm{~kg} / 100 \\
\text { dec }\end{array}$ & $\begin{array}{lccc}\text { Save } \quad \& & \text { Safe } & \text { Agroscience } \\
\text { Bangladesh } & & \end{array}$ \\
\hline Oxy Pol & $\begin{array}{l}\text { Sodium Percarbonate- } \\
13.5 \%+\mathrm{H}_{2} \mathrm{O}_{2}\end{array}$ & $250-500 / 100 \mathrm{dec}$ & Catapol Bioscience Ltd. \\
\hline Pure oxy & $\mathrm{H}_{2} \mathrm{O}_{2}$ & $1 \mathrm{~kg} / 100 \mathrm{dec}$ & Al Madina \\
\hline Oxygrow & $\begin{array}{l}\mathrm{O} 2 \quad \text { promoter } \\
(\mathrm{H} 2 \mathrm{O} 2 / \mathrm{Ca} 2 \mathrm{O} 2)\end{array}$ & $500 \mathrm{gm} / 100 \mathrm{dec}$ & Century Agro Ltd. \\
\hline Oxy gold & Sodium Percarbonate & $250-500 / 100 \mathrm{dec}$ & Fishtech (BD) Limited \\
\hline Oxysun & $\begin{array}{l}\text { Sodium } \quad \text { peroxide, } \\
\text { calcium } \\
\text { magnesium oxide }\end{array}$ & $500 \mathrm{gm} / 100 \mathrm{dec}$ & Rals Agro ltd., Bangladesh \\
\hline Best oxygen & Sodium percarbonate & $250-500 \mathrm{~g} / 100 \mathrm{dec}$ & Univet Ltd. \\
\hline $\begin{array}{l}\text { Fish care } \\
\text { powder }\end{array}$ & $\begin{array}{l}\text { Oxide of } \mathrm{Ca}, \mathrm{P}, \mathrm{S}, \mathrm{Mn} \text {, } \\
\mathrm{Mg}, \mathrm{Cu}, \mathrm{N}\end{array}$ & $1 \mathrm{~kg} / 33$ dec. & S.S.S Agro care ltd. \\
\hline Fish curepas & $\begin{array}{l}\text { Oxide of } \mathrm{Ca}, \mathrm{P}, \mathrm{S}, \mathrm{Mn} \text {, } \\
\mathrm{Mg}, \mathrm{Cu}, \mathrm{N}\end{array}$ & $1 \mathrm{~kg} / 33$ dec. & M.R. Food and Protein Industries \\
\hline Oxywell & $\begin{array}{l}\text { Sodium percarbonate, } \\
\text { Tetra acetyl ethylene di } \\
\text { amine }\end{array}$ & $150-200 \mathrm{~g} / 4046.86 \mathrm{~m}^{2}$ & First Care Agro Ltd. \\
\hline Metoxy Tab & $\begin{array}{l}\text { Sodium percarbonate: } \\
99 \% \text { and oxygen release: } \\
13.60 \%\end{array}$ & $\begin{array}{l}\text { General dose } 500 \mathrm{gm} / 100 \mathrm{dec} \text {. In } \\
\text { case of high deficiency } 1 \mathrm{~kg} / 100 \mathrm{dec}\end{array}$ & Univet Ltd. \\
\hline Oxy Ton & $\begin{array}{l}\text { Sodium percarbonate- } \\
90 \% \text { and others } 10 \%\end{array}$ & $\begin{array}{l}\text { General dose } 200-250 \mathrm{gm} / 100 \mathrm{dec} \text {. } \\
\text { In case of high deficiency } 400-500 \\
\mathrm{gm} / 100 \mathrm{dec}\end{array}$ & Agrosol Bangladesh Company \\
\hline U-Oxy & $\begin{array}{l}\text { Sodium percarbonate- } \\
17 \%\end{array}$ & $\begin{array}{l}\text { General dose } 250-500 \mathrm{gm} / 100 \mathrm{dec} . \\
\text { In case of high deficiency } 500-800 \\
\mathrm{gm} / 100 \mathrm{dec}\end{array}$ & Uttara Tread bd \\
\hline
\end{tabular}

\subsubsection{AMDC used as stress reducer}

The available stress reducer were Ossi-C, Charger gel, Biomin Pondlife, Profs, Eskavit-C, Vitamin C -Soul, Energy plus, Osmosaline, Vita X-CK etc. The active ingredients of such medicines were mainly vitamin-C, betain, glucan, polyssceharides, beta-glucans, oxolinic acid bitaglucan (Table 11). 
Table 11. AMDC used as stress reducer.

\begin{tabular}{|c|c|c|c|}
\hline Trade name & Active ingredients & Doses/3-6 ft water & Sources \\
\hline Glucovet Premix & Ascorbic acid (Vit-C) & $1-2 \mathrm{~g} \mathrm{~L}-1$ & ACME Pharmaceuticals Co. Ltd. \\
\hline Ossi-C & $\begin{array}{l}\text { Oxolinic Acid, Beta glucan, } \\
\text { Vitamin C }\end{array}$ & $4-5 \mathrm{~g} / \mathrm{Kg}$ feed & Fishtech (BD) Limited \\
\hline Osmosaline & Betain & $5-10 \mathrm{~g} / 100$ Litre & Eon Animal Health \\
\hline Cevit Aqua & L-ascorbic acid (Vit-C) & $2-3 \mathrm{gm} / \mathrm{kg}$ feed & Square AgroVet Division \\
\hline Vita X-CK & Vit-C,K & $1 \mathrm{gm} / 3 \mathrm{~kg}$ feed & Eon Animal Health \\
\hline Eskavit-C & Vit-C $100 \%$ & $1 \mathrm{~g} \mathrm{~kg}-1$ feed & SK+F Pharmaceuticals Ltd. \\
\hline Vitamin C-Soul & Vit-C $100 \%$ & $3 \mathrm{~g} /$ Feed & Eon Animal Health \\
\hline C-Aqua & Vit-C 100\% & $2-4 \mathrm{~g} /$ Feed & ACI Animal Health \\
\hline Oralyte & Vita A with Electrolyte Premis & $1 \mathrm{gm} /$ liter water & Opsonin Agrovet Division \\
\hline Energy plus & Vita C + Glucose & $1-2 \mathrm{gm} /$ liter water & ACI Animal Health \\
\hline Vitmin C-Sol & Vita C-99\% & $2-3 \mathrm{gm} /$ feed & Advanced Agrotech (BD) Ltd \\
\hline Stress remover saline & $\mathrm{NaHCO}_{3}, \mathrm{Nacl}, \mathrm{KCl}$, Vit A, $\mathrm{ZnSO}_{4}$ & $0.5-1 \mathrm{gm} / \mathrm{litter}$ & VnF Agro Ltd. \\
\hline Gluco-c Power & Vita C + Glucose & $0.5-1 \mathrm{gm} / \mathrm{ton}$ & VnF Agro Ltd. \\
\hline Vita Fast & Ascorbic acid & $1-2 \mathrm{gm} /$ Feed & VnF Agro Ltd. \\
\hline Verno $\mathrm{C}$ & Vita-C & $0.5-1 \mathrm{gm} /$ feed & Verno Bio-Solutions Ltd. \\
\hline Renalyte-F & $\mathrm{NaHCO}_{3}, \mathrm{Nacl}, \mathrm{KCl}$, Dextrose & $3 \mathrm{~kg} / \mathrm{acere}$ & Renata Animal Health \\
\hline Aqualyte & $\mathrm{NaHCO}_{3}, \mathrm{Al}_{2} \mathrm{O}_{3}, \mathrm{CaO}$ & $3-5 \mathrm{~kg} / 100 \mathrm{dec}$ & Agrosol Bangladesh Company \\
\hline Fish Saline & $\begin{array}{l}\mathrm{NaHCO}_{3}, \mathrm{NaCl}, \mathrm{KCl}, \text { Vitamin, } \\
\text { Glucose }\end{array}$ & $0.5-1 \mathrm{gm} / \mathrm{litter}$ & Uttara Tread bd. \\
\hline Vitamix C Plus & Vitamin-C & 1gm/litter & Uttara Tread bd. \\
\hline
\end{tabular}

\subsubsection{AMDC used as growth promoter}

All of the growth promoters are essential for the rapid increase of the fish population. Some of these chemicals, such as aqua boost, fish vita plus, Aqua savour, Eon fish grower, Aqua gel, Panvit aqua, Charger gel, Vitamin $\mathrm{F}$ aqua, Aci mix super fish, and others, help to improve the disease-prevention abilities of fish. Aqua boost is a type of growth promoter that is being used to boost the immune system of fish. Megavit aqua also helps to boost the hatching rate, and Aquamin is beneficial in the development of fishes' bones. Aqua savour and Grow quick both aid in the recovery of malnourished fishes as well as the improvement of their physical condition in general (Table 12).

Table 12. AMDC used as growth promoter.

\begin{tabular}{llll}
\hline Trade name & Active ingredients & Doses & Sources \\
\hline Eon Fish Grower & Vitamin + Mineral premix & $1.5-3 \mathrm{gm} / \mathrm{kg}$ feed & Eon Animal Health \\
\hline Aqua savor & Amino acid premix & $2-3 \mathrm{~kg} / \mathrm{MT}$ feed & Eon Animal Health \\
\hline Spa & $\begin{array}{l}\text { Protein, Cholesterol 116arotenoid, Vit-D, } \\
\text { Ca }\end{array}$ & $10-15 \mathrm{ml} / \mathrm{kg}$ feed & Eon Animal Health \\
& Vitamin + Mineral premix & $7-10 \mathrm{ml} / \mathrm{kg}$ feed & ACI Animal Health \\
\hline Fish Gel & Mineral premix + Herbal growth factor & $2-4 \mathrm{ml} / \mathrm{kg}$ feed & ACI Animal Health \\
\hline Aquamin & $\begin{array}{l}\text { Vitamin }+ \text { Mineral }+ \text { Amnion acid+ } \\
\text { Calcium and probiotics }\end{array}$ & $1 \mathrm{~kg} / \mathrm{ton}$ feed & ACI Animal Health \\
\hline ACI Fish Premix & Vitamin, mineral + antioxydent & $1 \mathrm{~kg} / \mathrm{ton}$ Feed & ACI Animal Health \\
\hline Acimix super-fish & Crude-Protein, Fat, Moisture, Ash, Fiber, $1-2 \mathrm{gm} / \mathrm{kg}$ feed & ACI Animal Health \\
\hline Krill Meal & $\begin{array}{l}\text { CHO, Ca, and P } \\
\text { Vita Health Plus }\end{array}$ & $\begin{array}{l}\text { Multivitamin, Nicotinamide, Biotin, Lysine, }, 1 \mathrm{ml} / \mathrm{kg} \text { feed } \\
\text { Foic acidETC }\end{array}$ & Ultimate (bd) Ltd. \\
\hline Han-Vita & Vita-C, E, B1, K3, Sorbitol, Multienzyme & $2-3 \mathrm{gm} / \mathrm{kg}$ feed & Ultimate (bd) Ltd. \\
\hline Aqua Live Care & $\begin{array}{l}\text { Liver extract, Yeast Amini acid, protein, } \\
\text { biotin, extract, sorbitol, vita-B }\end{array}$ & $2-3 \mathrm{ml} / \mathrm{kg}$ feed & Advanced Agrotech (BD) Ltd \\
\hline Growth Gel & $\begin{array}{l}\text { Essential vitamins, lysine, Methionine and } \\
\text { herbs }\end{array}$ & $7-10 \mathrm{ml} / \mathrm{kg}$ feed & Advanced Agrotech (BD) Ltd \\
\hline Multi Grow & $\begin{array}{l}\text { Multivitamin, Multimineral, Biotin, Folic } \\
\text { acid, Taaurine, Inositol }\end{array}$ & $2-3 \mathrm{gm} / \mathrm{kg}$ feed & Advanced Agrotech (BD) Ltd \\
\hline Butamin & Cyanocobalamin, Methyl Hydroxybenzoat, & $5 \mathrm{ml} / \mathrm{kg}$ feed & Advanced Agrotech (BD) Ltd \\
\hline
\end{tabular}




\begin{tabular}{|c|c|c|c|}
\hline & Methylethyl-phosphonic acid & & \\
\hline Growth Magic & $\begin{array}{l}\text { Mutivitamin, Multienzyme, Multimineral, } \\
\text { amino acid }\end{array}$ & $3-5 \mathrm{gm} / \mathrm{kg}$ feed & Agrosol Bangladesh Company \\
\hline AVM- Aquamix & $\begin{array}{l}\text { Mutivitamin, Multienzyme, Multimineral, } \\
\text { amino acid }\end{array}$ & $3-5 \mathrm{gm} / \mathrm{kg}$ feed & Agrosol Bangladesh Company \\
\hline Verno Vit Aqua & Vitamin Premix & $2.5-5 \mathrm{~kg} / \mathrm{ton}$ feed & Verno Bio-Splutions Ltd. \\
\hline Saltose plus & Probiotics and Enzyme & $\begin{array}{l}250-500 / \quad \text { ton } \\
\text { Feed }\end{array}$ & Opsonin Agrovet Division \\
\hline $\begin{array}{l}\text { Biomin Aqua } \\
\text { Boost }\end{array}$ & Amino acid, Immune component, & $3-5 \mathrm{gm} / \mathrm{kg}$ feed & Reneta Animal Health \\
\hline Fish Probiotics & $\begin{array}{l}\text { Bacillus subtilis, Nitro fire, photosynthetic } \\
\text { bacteria }\end{array}$ & $\begin{array}{l}1000-1500 \\
\mathrm{gm} / 100 \mathrm{dec}\end{array}$ & VnF Agro Lid. \\
\hline V-F. GEL & $\begin{array}{l}\text { Vit } \mathrm{B}_{12} \text {, lysine, DL Methionine, Colin } \\
\text { chloride, Biotin }\end{array}$ & $\begin{array}{l}0.5-10 \quad \mathrm{ml} / \mathrm{kg} \\
\text { feed }\end{array}$ & VnF Agro Lid. \\
\hline Verno Boost & Growth promoter & $1-2 \mathrm{gm} / \mathrm{kg}$ feed & Verno Bio-Solutions Ltd. \\
\hline Multisol-G & Multivitamins and Multiminerals & $1-1.5 \mathrm{gm} / \mathrm{kg}$ feed & Univet Ltd. \\
\hline Chelamin Plus & Chelate $\mathrm{Ca}, \mathrm{Mn}, \mathrm{K}, \mathrm{Zn}, \mathrm{Fe}, \mathrm{Cu}, \mathrm{Cr}, \mathrm{Co}$ & $10 \mathrm{ml} / \mathrm{kg}$ feed & Univet Ltd. \\
\hline $\begin{array}{l}\text { Panvit Aqua } \\
\text { Liquid }\end{array}$ & $\begin{array}{l}\text { Vit } A, D_{3}, B_{1}, B_{2}, B_{6} \text {, Nicotinamide and Vit- } \\
\text { C }\end{array}$ & $\begin{array}{l}0.5-10 \quad \mathrm{ml} / \mathrm{kg} \\
\text { feed }\end{array}$ & Square AgroVet Division \\
\hline Aqua GEL gel & Amino acids, $\omega_{3} \omega_{6}$ fatty acid and Minerals & $\begin{array}{l}10-15 \quad \mathrm{gm} / \mathrm{kg} \\
\text { feed }\end{array}$ & Square AgroVet Division \\
\hline $\begin{array}{l}\text { Square Aquamix } \\
\text { Powder }\end{array}$ & $\begin{array}{l}\text { Vitamins, Amino acids, Minerals, Prebiotic } \\
\text { and Antioxidant }\end{array}$ & $1 \mathrm{gm} / \mathrm{kg}$ feed & Square AgroVet Division \\
\hline Provit gel & $\begin{array}{l}\text { Vitamin A, B1,B2,B6, C, D, Niacinamide, } \\
\text { Calcium pentothinate, Folic acid , Inositol, } \\
\text { Lysine, Methionine, Protein hydrolyzate }\end{array}$ & $10 \mathrm{~g} / \mathrm{kg}$ feed & First care Agro. Ltd. \\
\hline Fibosoel. & B-Glucan and mannos polymer & $\begin{array}{l}200-300 \quad \mathrm{~g} / \mathrm{MT} \\
\text { feed }\end{array}$ & Eon Animal Health \\
\hline Aqumin & $\begin{array}{l}\mathrm{Cu}, \mathrm{Co}, \mathrm{Mg}, \mathrm{Fe}, \mathrm{Zn}, \mathrm{I}, \mathrm{Ca}, \mathrm{P}, \mathrm{D}, \mathrm{L} . \\
\text { Mithiolin, L-lysin } \mathrm{HCl}\end{array}$ & $1 \mathrm{gm} / \mathrm{kg}$ feed & ACI Animal Health \\
\hline Grow Fast & High protein, Fat and Mineral & $\begin{array}{l}5-10 \% \text { of body } \\
\text { weight }\end{array}$ & ACI Animal Health \\
\hline Ayumin powder & Mineral and herbs & $5-10 \mathrm{~kg} /$ ton feed & ACI Animal Health \\
\hline Eskavit & Vitamins, Minerals and Premix & $2.5 \mathrm{~kg} / \mathrm{ton}$ feed & SK+F Pharmaceuticals Ltd. \\
\hline Aqua boost & Organic acid, $ß$-glucan & $500 \mathrm{~g} /$ ton feed & Novartis pharmaceuticals ltd. \\
\hline Fish vita plus & $\begin{array}{l}\text { Vitamin, mineral and amino acid } \\
\text { supplement }\end{array}$ & $\begin{array}{l}200-300 \mathrm{ml} / 100 \\
\mathrm{~kg} \text { feed }\end{array}$ & Rals Agro ltd. \\
\hline Grow fast & $\begin{array}{l}\text { Vitamin, mineral and amino acid } \\
\text { supplement }\end{array}$ & $\begin{array}{l}200-300 \mathrm{ml} / 100 \\
\mathrm{~kg} \text { feed }\end{array}$ & Rals Agro ltd. \\
\hline Growmax & Vit + mineral + amino acid & $2.5 \mathrm{~kg} / \mathrm{ton}$ feed & Penta Agrovet ltd. \\
\hline Megavit Aqua & $\begin{array}{l}\text { Vitamin, mineral and amino acid } \\
\text { supplement }\end{array}$ & $100 \mathrm{~g} / 100 \mathrm{~kg}$ feed & Novartis pharmaceuticals ltd. \\
\hline Nature aqua GP & Vit + mineral + amino acid & $2.5 \mathrm{~kg} /$ ton feed & Nature care ltd. \\
\hline Orgavit aqua & $\begin{array}{l}\text { Vitamin, mineral and amino acid } \\
\text { supplement }\end{array}$ & $100 \mathrm{~g} / 100 \mathrm{~kg}$ feed & Organic pharmaceuticals ltd. \\
\hline Safe Gurd & Vitamin, Enzyme and Probiotics & $\begin{array}{l}\text { No } \\
\text { recommendation } \\
\text { found }\end{array}$ & SK+F Pharmaceuticals Ltd. \\
\hline NutriGel & Vitamin, mineral and Probiotics & $\begin{array}{l}\text { No } \\
\text { recommendation } \\
\text { found }\end{array}$ & SK+F Pharmaceuticals Ltd. \\
\hline Esklina & $100 \%$ organic Sprolina & $\begin{array}{l}\text { No } \\
\text { recommendation } \\
\text { found }\end{array}$ & SK+F Pharmaceuticals Ltd. \\
\hline Acilina & $100 \%$ natural Sprolina & $\begin{array}{l}15-30 \mathrm{gm} / \mathrm{kg} \\
\text { feed }\end{array}$ & ACI Animal Health \\
\hline Rena Fish & Vit A, B, C, D3, E, K, Cu, Mn, Fe, Co etc. & $1 \mathrm{Kg} /$ ton feed & Reneta Animal Health \\
\hline Charger Gel & $\begin{array}{l}\text { 1-3 D-Glucan, Polysaccharides, Btain, Beta } \\
\text { Glucan }\end{array}$ & $6-8 \mathrm{~g} / \mathrm{kg}$ feed & Fishtech (BD) Limited \\
\hline
\end{tabular}




\begin{tabular}{|c|c|c|c|}
\hline & Anti oxydent etc. & & \\
\hline Vitamix $F$ aqua & Vit + mineral + amino acid & $2.5 \mathrm{~kg} / \mathrm{ton}$ feed & The Acme laboratories Ltd. \\
\hline Catamin & Vitamin and mineral & $2-3 \mathrm{~L} / 100 \mathrm{dec}$ & Catapol Bioscience ltd. \\
\hline Aqua Boost & Organic acid, Beta-Glucan & $500 \mathrm{~g} / \mathrm{ton}$ feed & Novartis Pharmaceuticals Ltd. \\
\hline Leabon aqua & Saccharomyces cerivisiae & $3-5 \mathrm{gm} / \mathrm{kg}$ feed & Reneta Animal Health \\
\hline Power Gel & $\begin{array}{l}\text { Cyanocobalamin, } \\
\text { Methyle Hyydroxybenzoat }\end{array}$ & $6-8 \mathrm{ml} / \mathrm{kg}$ feed & $\begin{array}{l}\text { Save \& Safe Agroscience } \\
\text { Bangladesh }\end{array}$ \\
\hline Ultar Grow & $\begin{array}{l}\text { Cyanocobalamin, } \\
\text { Methyle Hyydroxybenzoat }\end{array}$ & $5 \mathrm{ml} / \mathrm{kg}$ feed & Ultimate (bd) Ltd. \\
\hline Growth Master & $\begin{array}{l}\text { Vitamin, Mineral, Biotin, Folic acid, B- } \\
\text { Glucan \& mannan }\end{array}$ & $2-3 \mathrm{gm} / \mathrm{kg}$ feed & $\begin{array}{l}\text { Save \& Safe Agroscience } \\
\text { Bangladesh }\end{array}$ \\
\hline Growmax Super & $\begin{array}{l}\text { Vitamin, Mineral, Biotin, Folic acid, B- } \\
\text { Glucan \& mannan }\end{array}$ & $1.5 \mathrm{gm} / \mathrm{kg}$ feed & $\begin{array}{l}\text { Save \& Safe Agroscience } \\
\text { Bangladesh }\end{array}$ \\
\hline Grow Fast & $\begin{array}{l}\text { Vitamin, mineral and amino acid } \\
\text { supplement }\end{array}$ & $\begin{array}{l}200-300 \mathrm{ml} / 100 \\
\mathrm{~kg} \text { feed }\end{array}$ & Rals Agro \\
\hline Promim Vit-Aqua & $\begin{array}{l}\text { Vit A, Vit B, Vita-K }{ }_{3} \text { Complex, Vita-D, } \\
\text { Vita-E, Vita-C, Co, I, Na, Zn, Cu, Ca, Fe, } \\
\text { Mn Se, Lysine, colin chloride }\end{array}$ & $\begin{array}{l}200-300 \mathrm{gm} / 100 \\
\mathrm{~kg} \text { Feed }\end{array}$ & Promim Agro vet Industries \\
\hline Provita Gel & $\begin{array}{l}\text { Multivitamin, Ca, Folic acid, lysine, } \\
\text { methionine }\end{array}$ & $10 \mathrm{gm} / \mathrm{kg}$ feed & First Care Agro Ltd. \\
\hline U- Fish Growth & $\begin{array}{l}\text { Vit A, Vit B, Vita-K }{ }_{3} \text { Complex, Vita-D, } \\
\text { Vita-E, Vita-C, Co, I, Na, Zn, Cu, Ca, Fe, } \\
\text { Mn Se, Lysine, colin chloride, } \\
\text { Enzyme,biotin }\end{array}$ & $2 \mathrm{gm} / \mathrm{kg}$ feed & Uttara Tread bd. \\
\hline
\end{tabular}

\subsubsection{Probiotics used in fish culture}

Probiotics work by supplying nutrients, enzymes for improved digestion, regulating the immune system, and boosting the immunological response to harmful microorganisms. Lactic acid bacteria such as Lactobacillus sp., Bacillus sp., Enterococcus sp., and yeast Saccharomyces cerevisiae are the most often utilized probiotics in aquaculture. The study area included 21 probiotics items that were commonly used by farmers (Table 13).

Table 13. Probiotics used in freshwater aquaculture in south-eastern Bangladesh.

\begin{tabular}{|c|c|c|c|c|}
\hline Trade name & Compositions & Purpose of use & Doses & Source \\
\hline Profs & $\begin{array}{l}\text { Bacillus sp. And Padiococcus } \\
\text { sp. }\end{array}$ & $\begin{array}{l}\text { Control vibriosis, } \\
\text { luminescent bacteria }\end{array}$ & $\begin{array}{ll}\begin{array}{l}50-70 \\
\text { dec }\end{array} & \mathrm{gm} / 33 \\
\end{array}$ & Eon Animal Health \\
\hline Aqua photo & $\begin{array}{l}\text { Bacillus subtilis and } \\
\text { Rhodoseudomonas }\end{array}$ & $\begin{array}{l}\text { Control unwanted gas, } \\
\text { sediment and increase } \\
\text { growth of plankton }\end{array}$ & $\begin{array}{l}50-70 \mathrm{ml} / 100 \\
\mathrm{dec}\end{array}$ & ACI Animal Health \\
\hline Navio Plus & $\begin{array}{l}\text { Bacillus subtilis } \\
\text { Bacillus licheniformis, Bacillus } \\
\text { megaterim, } \\
\text { Lactobacillus Acidophilis } \\
\text { Lactobacillus plantarum }\end{array}$ & $\begin{array}{l}\text { Increase growth rate } \\
\text { and disease preventive } \\
\text { power }\end{array}$ & 1-3 gm/Feed & ACI Animal Health \\
\hline Uni ecosense & $\begin{array}{l}\text { B. subtilis, } \\
\text { B. licheniformis, } \\
\text { B. polymyxa, } \\
\text { B. pumuls, } \\
\text { Thiobacillus deniftrificans, } \\
\text { Aspergillus oryzae, Aspergillus } \\
\text { niger, Pseudomonas } \\
\text { denetrificans, } \\
\text { Bacillus coagulans }\end{array}$ & & $\begin{array}{l}\text { Fish:250- } \\
300 \mathrm{~g} / 4046.86 \\
2 \mathrm{~m} \\
\text { Shrimp:75- } \\
100 \mathrm{~g} / 4046.86 \\
2 \mathrm{~m}\end{array}$ & First care \\
\hline Eco Marine & $\begin{array}{l}\text { Bacillius subtilis, B. pumilis, } B . \\
\text { amylolichenifacions } \\
\text { megaterium. }\end{array}$ & $\begin{array}{l}\text { Control vibriosis and } \\
\text { luminescent bacteria }\end{array}$ & $\begin{array}{l}3-4 \text { tablet } / 100 \\
\text { dec }\end{array}$ & $\begin{array}{l}\text { Organic } \\
\text { Pharmaceuticals Ltd. }\end{array}$ \\
\hline Aqua Gold & Rhodopseudomonas sp. & $\begin{array}{l}\text { Increase growth rate } \\
\text { and disease preventive } \\
\text { power }\end{array}$ & $2 \mathrm{ml} / 100 \mathrm{dec}$ & $\begin{array}{l}\text { Organic } \\
\text { Pharmaceuticals Ltd. }\end{array}$ \\
\hline
\end{tabular}




\begin{tabular}{|c|c|c|c|c|}
\hline Aqua Magic & \begin{tabular}{lr}
\multicolumn{2}{l}{ Azobacter chorococcum } \\
Bacillus cereus & \\
Bacillus megaterium & Bacillus \\
subtilis Candida & utilis \\
Lactobacillus & fermentus \\
Lactobacillus & planterum \\
Rhodotorulla $\mathrm{sp}$. &
\end{tabular} & $\begin{array}{l}\text { Control unwanted gas, } \\
\text { sediment and increase } \\
\text { growth of plankton }\end{array}$ & $\begin{array}{ll}5-6 & \mathrm{~kg} / 100 \\
\mathrm{dec} & \end{array}$ & Fish tech (BD) Limited \\
\hline $\begin{array}{l}\text { Aqua Star } \\
\text { Grow Out }\end{array}$ & $\begin{array}{l}\text { Bacillus } \mathrm{sp} \\
\text { Lactobacillus } \\
\text { Enterococcus } \mathrm{sp} \\
\text { Pedicocus } \mathrm{sp}\end{array}$ & $\begin{array}{l}\text { Increase beneficial } \\
\text { bacteria, increase feed } \\
\text { attraction } \\
\text { increase fish weight }\end{array}$ & $3-5 \mathrm{gm} /$ feed & Reneta Animal Health \\
\hline Procon-PS & $\begin{array}{l}\text { Bacillus sp., Rhodococcus, and } \\
\text { Rhodobacter }\end{array}$ & $\begin{array}{l}\text { Control unwanted gas, } \\
\text { sediment and arrests } \\
\text { the pathogens }\end{array}$ & $\begin{array}{l}5 \mathrm{~L} / \mathrm{hac}(1 \mathrm{~m} \\
\text { depth) }\end{array}$ & Rals Agro Ltd. \\
\hline Super Biotic & Bacillus sp. & $\begin{array}{l}\text { Reduce pathogenic } \\
\text { bacteria in water }\end{array}$ & $\begin{array}{lll}\begin{array}{l}1-2 \\
\text { dec }\end{array} & \mathrm{kg} / & 100 \\
\end{array}$ & CP Aquaculture \\
\hline Super PS & Rodobacter sp., Rodococcus sp. & $\begin{array}{l}\text { Improve soil quality } \\
\text { and reduce toxic gas } \\
\text { from bottom }\end{array}$ & 4-6 L/100 dec & CP Aquaculture \\
\hline Pond care & S. faecalis and other bacteria & $\begin{array}{l}\text { Inhibit pathogenic } \\
\text { bacteria }\end{array}$ & 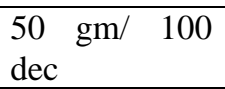 & SK+F Animal Health \\
\hline Eco-Life & $\begin{array}{l}\text { Bacillus subtilis } \\
\text { Bacillus } \\
\text { Lactobacillus } \\
\text { Nitrosomonas sp } \\
\text { Nitrobacter sp } \\
\text { Yeast }\end{array}$ & $\begin{array}{l}\text { Improve soil quality } \\
\text { and inhibit pathogenic } \\
\text { bacteria }\end{array}$ & $\begin{array}{l}200-300 \\
\mathrm{gm} / 100 \mathrm{dec}\end{array}$ & $\begin{array}{ll}\text { Agrosol } & \text { Bangladesh } \\
\text { Company } & \end{array}$ \\
\hline First-Ecosafe & $\begin{array}{l}\text { Bacillus subtilis } \\
\text { Bacillus Coagulans } \\
\text { Bacillus megaterium } \\
\text { Lactobacillus acidophil } \\
\text { Aspergillus, } \\
\text { Nitrosomonas sp }\end{array}$ & $\begin{array}{lr}\text { Inhibit } & \text { pathogenic } \\
\text { bacteria } & \text { like } \\
\text { Salmonella, } & \text { Aero } \\
\text { monas, E. Eoli, Vibrio }\end{array}$ & $\begin{array}{l}200-250 \\
\mathrm{gm} / 100 \mathrm{dec}\end{array}$ & First Care Agro Ltd. \\
\hline PPM & Probiotics & $\begin{array}{l}\text { Improve soil quality } \\
\text { and reduce toxic gas } \\
\text { from bottom }\end{array}$ & $\begin{array}{cc}250 & \mathrm{gm} / 100 \\
\mathrm{dec} & \end{array}$ & $\begin{array}{l}\text { Verno } \\
\text { Ltd. }\end{array}$ \\
\hline Metprob & $\begin{array}{l}\text { Nitrosomonas } \mathrm{sp} \\
\text { Nitrobacter } \mathrm{sp} \\
\text { Bacillus subtilis } \\
\text { Rhodobacter } \\
\text { Padiococcus } \mathrm{sp} \text {. } \\
\text { Saccharomyces cerivisiae } \\
\end{array}$ & $\begin{array}{l}\text { Reduce toxic gas from } \\
\text { bottom, improve water } \\
\text { quality }\end{array}$ & $\begin{array}{l}250-500 \\
\mathrm{gm} / 100 \mathrm{dec}\end{array}$ & Univet Ltd. \\
\hline Aqua Rich & $\begin{array}{l}\text { Bacillus subtilis, } \\
\text { Photosynthetic bacteria, } \\
\text { Nitrifying bacteria } \\
\text { Nitrobacteria sp } \\
\text { Lactic acid bacteria, } \\
\text { Yeast, Enzyme }\end{array}$ & $\begin{array}{l}\text { Reduce toxic gas from } \\
\text { bottom, control bloom, } \\
\text { remove black Soil }\end{array}$ & $\begin{array}{ll}500 & \mathrm{gm} / 100 \\
\mathrm{dec} & \end{array}$ & Ultimate (bd) Ltd. \\
\hline Delight Aqua & $\begin{array}{l}\text { Bacillus subtilis } \\
\text { Nitrobacteria, } \\
\text { Nitrococcus } \\
\text { Photosynthetic bacteria }\end{array}$ & $\begin{array}{l}\text { Reduce toxic gas from } \\
\text { bottom, control bloom, } \\
\text { remove black Soil }\end{array}$ & $\begin{array}{ll}600 & \mathrm{gm} / 100 \\
\mathrm{dec} & \end{array}$ & Ultimate (bd) Ltd. \\
\hline Aqua Life $\mathrm{S}$ & $\begin{array}{l}\text { Bacillus subtilis } \\
\text { Bacillus megaterium } \\
\text { Lactobacillus acidophil } \\
\text { Nitrosomonas sp } \\
\text { Nitrobacter sp } \\
\text { Saccharomyces cerivisiae } \\
\text { Yeast }\end{array}$ & $\begin{array}{l}\text { Reduce toxic gas from } \\
\text { bottom, improve water } \\
\text { quality, improved } \\
\text { biological way }\end{array}$ & $\begin{array}{ll}500 & \mathrm{gm} / 100 \\
\mathrm{dec} & \end{array}$ & $\begin{array}{l}\text { Save \& Safe } \\
\text { Agroscience } \\
\text { Bangladesh }\end{array}$ \\
\hline Aqua Clear S & $\begin{array}{l}\text { Bacillus subtilis } \\
\text { Bacillus } \quad \text { megaterium }\end{array}$ & $\begin{array}{l}\text { Reduce toxic gas from } \\
\text { bottom, improve water }\end{array}$ & $\begin{array}{ll}500 & \mathrm{gm} / 100 \\
\mathrm{dec} & \\
\end{array}$ & $\begin{array}{c}\text { Advanced Agrotech } \\
\text { (BD) Ltd }\end{array}$ \\
\hline
\end{tabular}




\begin{tabular}{|c|c|c|c|c|}
\hline & $\begin{array}{l}\text { Lactobacillus acidophil } \\
\text { Nitrosomonas sp } \\
\text { Nitrobacter sp } \\
\text { Saccharomyces cerivisiae }\end{array}$ & $\begin{array}{l}\text { quality, improved } \\
\text { biological way }\end{array}$ & & \\
\hline Aqua Bac P & $\begin{array}{l}\text { Bacillus amyloliquefaciencs, } \\
\text { Bacillus pumilus, } \mathrm{CaCO}_{3} \text {, }\end{array}$ & $\begin{array}{ll}\text { Reduce toxic gas from } & 50-75 / \\
\text { bottom, improve water } & \text { dec } \\
\text { quality, improved } & \\
\text { biological way } & \end{array}$ & 100 & $\begin{array}{l}\text { Advanced Agrotech } \\
\text { (BD) Ltd }\end{array}$ \\
\hline
\end{tabular}

\subsubsection{Antibiotics for disease treatment}

While only a few antibiotics have been approved for use in aquaculture, and precise data on their use is difficult to come by, at least two critically important antibiotics, tetracyclines and oxolinic acid, a third generation quinolone, are in routine use in Bangladesh and adjacent regions, respectively, to control specific diseases and bacterial infections in the aquaculture industry. Several antimicrobials, including antibiotics, were proposed for inclusion in fish feed regulations in 2011, and some of these were approved by the Bangladesh government in accordance with acceptable ranges of presence of these substances and the use of antibiotics, as well as the use of antibiotics in fish feed regulations in 2011. The present study found 19 antibiotics in the south eastern Bangladesh (Table 14).

Table 14. List of antibiotics for disease treatment in the study area.

\begin{tabular}{|c|c|c|c|}
\hline Trade name & Active ingredients & Doses & Source \\
\hline Oxy-D Vet & $\begin{array}{l}\text { Oxytetracycline } \\
\text { Doxycycline } 10 \%\end{array}$ & $\begin{array}{l}5-10 \mathrm{~g} / \mathrm{Kg} \text { body wt. for } 5-7 \\
\text { days }\end{array}$ & Eon Animal Health \\
\hline EST-Vet & $\begin{array}{l}\text { Erithromycine thiocyanate, } \\
\text { Suiphadyazine, Trimethoprim }\end{array}$ & $\begin{array}{l}100-150 \mathrm{gm} / 1000 \mathrm{~kg} \text { body } \\
\text { wt. for 3-5 days }\end{array}$ & Eon Animal Health \\
\hline Ablaze & $\begin{array}{l}\text { Vitamin, } \\
\text { Antimicrobial agents }\end{array}$ & $\begin{array}{l}150-200 \mathrm{gm} / 1000 \mathrm{~kg} \text { body } \\
\text { wt. }\end{array}$ & Eon Animal Health \\
\hline Bactitab & Oxytetracycline $20 \%$ & $\begin{array}{l}5 \mathrm{gm} / \mathrm{kg} \text { body weight } 5-7 \\
\text { days }\end{array}$ & ACI Animal Health \\
\hline Acimox (vet) powder & Amoxicillin trihydrate & $1 \mathrm{gm} / 1 \mathrm{~kg}$ feed & ACI Animal Health \\
\hline Cotrim-vet & $\begin{array}{l}\text { Sulphamethoxazole } \\
\text { trimethoprim }\end{array}$ & $0.5 \mathrm{mg} / \mathrm{kg}$ body weight & Square AgroVet Division. \\
\hline Contrim (vet) bolus & Cotrimoxazole & $\begin{array}{llll}1 & \text { bolus/10-12 } & \mathrm{kg} & \text { body } \\
\text { weight }\end{array}$ & Square AgroVet Division \\
\hline Otetra (vet) powder 50 & Oxytetracycline & $\begin{array}{l}\text { Mixed with feed; } 11-16 \\
\text { gm/100 kg body weight }\end{array}$ & Square AgroVet Division \\
\hline Oxin WS & Oxytetracycline $20 \%$ & $50 \mathrm{mg} / \mathrm{kg}$ body weight & $\begin{array}{l}\text { Navana pharmaceuticals } \\
\text { ltd. }\end{array}$ \\
\hline Oxysentin $20 \%$ & Oxytetracycline HCL BP & $\begin{array}{l}50-100 \mathrm{gm} / 100 \mathrm{~kg} \text { feed, } 5-7 \\
\text { days (for treatment) }\end{array}$ & $\begin{array}{l}\text { Novartis pharmaceuticals } \\
\text { ltd. }\end{array}$ \\
\hline Ranamox & Amoxicillin trihydrate & $\begin{array}{l}28-40 \mathrm{gm} / 100 \mathrm{bd} \text { of fish, } 10 \\
\text { days continuously }\end{array}$ & Renata Animal Health. \\
\hline Renamycin & Oxytetracycline & $\begin{array}{l}28-42 \mathrm{gm} / 100 \mathrm{~kg} \text { feed, } 10 \\
\text { days }\end{array}$ & Renata Animal Health \\
\hline Sulphatrim & Sulphadiazine & $\begin{array}{l}50 \mathrm{gm} / \mathrm{kg} \text { body weight, } 5-7 \\
\text { days }\end{array}$ & Square AgroVet Division \\
\hline Aquamycine & Oxytetracycline HCL 25\% & $1-2 \mathrm{~g} / \mathrm{Kg}$ feed for $5-7$ days & ACI Animal Health \\
\hline Chlorsteclin & Chlortetracycline & $\begin{array}{l}200-300 \mathrm{gm} / 100 \mathrm{~kg} \text { feed }(5- \\
7 \text { days) }\end{array}$ & $\begin{array}{l}\text { Novartis pharmaceuticals } \\
\text { ltd. }\end{array}$ \\
\hline Amoxifish & Amoxicillin trihydrate & $3-5 \mathrm{gm} / \mathrm{kg}$ feed & Fish tech \\
\hline Orgacycline $15 \%$ & Chlortetracycline & $\begin{array}{l}200-300 \mathrm{gm} / 100 \mathrm{~kg} \text { feed } 5-7 \\
\text { days }\end{array}$ & $\begin{array}{l}\text { Organic pharmaceuticals } \\
\text { ltd. }\end{array}$ \\
\hline Fish cure & Chlortetracycline HCL & $\begin{array}{l}500 \mathrm{gm} / 1000 \mathrm{~kg} \text { feed }(3-5 \\
\text { days) }\end{array}$ & Rals agro ltd. \\
\hline Argulex & Trichlorofon $40 \%$ & $12-13 \mathrm{ml} / \mathrm{dec}$ & Eon Animal Health \\
\hline
\end{tabular}




\section{Discussion}

Aquaculture generates a great deal of financial activity and transaction in the south-western portion of Bangladesh, and this is mostly owing to both the intensity and the extent of the nature of the aquaculture activity in this region. According to a number of prior studies, aquaculture in these specific locations might contribute to the regional and national demand for animal protein, as well as providing financial assistance to local farmers and, ultimately, to the gross domestic product (GDP) (Al-Asif et al., 2021; Ullah et al., 2020b). While the aquaculture industry has a direct relationship with the social and economic growth of an area, a small-scale and healthy farm may create enough money to support a nuclear family in a comfortable manner (Adhikary et al., 2018c; Adhikary et al., 2018a, 2018b; Al-Asif et al., 2015; Al-Asif and Habib, 2018; Ali et al., 2016; Hossain et al., 2017, 2015; Islam et al., 2017, 2014; Rahman et al., 2017a; Razeim et al., 2017; Sharif et al., 2015; Vaumik et al., 2017).

Approximately 33 businesses were found to be either manufacturing or selling aqua medicines, drugs, and chemicals (AMDC) items aimed at freshwater aquaculture in the south-eastern portion of Bangladesh, according to the results of the present study. However, study of Rahman et al. (2017b) suggested 24 companies were established and continuing their business in only Cumilla region and 30 nationwide companies were reported by the study of Al-Asif et al. (2021).

In the booklet of company (provided by the company), they gave in-depth information on the objectives, doses, duration, and mode of application of the substances they were using. The usage and effectiveness of several of the items, on the other hand, were seen differently by farmers. There have been reports of certain businesses providing technical help to the farmers (Al-Asif et al., 2021). As a result, the farmers are subjected to significant pressure from commercial enterprises to utilize a diverse range of products on their fields.

The present study revealed 330 AMDC products were available in the three districts of south eastern region of Bangladesh, while a nationwide investigation from 2011-2020 revealed 1484 items of products from different generic and business names are available around Bangladesh (Al-Asif et al., 2021), which is relevant with the present study.

Several kinds of predatory fish may get access to aquaculture farms via water sources or by being introduced to the farm with seed that has been brought in from outside (Nunny, 2020). The use of water management techniques in farms, such as periodic draining and preparations for the introduction of new stock, provides possibilities for farmers to exert a fair degree of control over predatory fish in their fields which might be costly for the farmers (Biswas et al., 2018; Ledesma, 2019; Otieno, 2019). It is relatively simple to implement control measures in outdoor nursery ponds, where the post-larvae and fry are vulnerable to predation not only by predatory fish, but also by insect larvae, notonectids, and other amphibians such as frogs. For example, spreading oil emulsions to prevent aerial breathing of insect larvae or fencing to prevent entry of frogs are both relatively simple and effective measures. Controlling avian and mammalian predators is more challenging than controlling rodents (Mogi, 2007; Ram Kumar, 2006).

Ectoparasites, which include single-celled protozoa, multi-celled trematodes, crustaceans, and arthropods, are a common infectious agent in freshwater fish and are found in a broad variety of environments. Ectoparasites are a kind of infectious pathogen that may infect freshwater fish and other aquatic organisms (Bruno et al., 2006; Iyaji and Eyo, 2009). There were many insecticides used on arugulas in the study area, including Engreb, Paratics, and Acemec 1 percent Oral Solution, among other things.

The present study suggested that various sort of pond preparation chemical and materials were used in the south eastern part of Bangladesh, including zeolite, lime and sometimes changes in water in a proper manner. While the study of Adhikary et al. (2018c), Chowdhury et al. (2015), Ullah et al. (2020) reported that lime, zeolite, fish toxin, insecticides and different fertilizers were used for the preparation and water quality management in Jashore, Sylhet and Noakhali regions respectively.

The usage of Geotox, Zeolite, Zeocare, lime, Mega Zeo Plus, Bio Aqua, Aquanone, and Zeo prime for pond preparation and water quality management by various farmers in Bangladesh was reported by Rahman et al. (2017b). When it came to fish aquaculture in Bangladesh, lime was by far the most frequently utilised chemical. Plankton is an essential food source for fish and a good indication of the overall productivity of a body of water (Akter et al., 2018; Siddika et al., 2013). In a water body, the qualitative and quantitative abundance of phytoplankton indicates whether the water body is oligotrophic or eutrophic, and therefore the productivity of the water body (Akter et al., 2018; Sipaúba-Tavares et al., 2011). A comprehensive understanding of phytoplankton quantity and quality in connection to environmental circumstances, both in time and space, has become a requirement for the production of high-quality fish (Chukwu and Afolabi, 2018; Hossain et al., 2019). The existence of zooplankton production is largely dependent on the availability of primary production (AntonPardo and Adámek, 2015; Bhaumik et al., 2006; Korhonen et al., 2011). Many plankton producers' chemicals 
were found in the study area while most of them are traditional fertilizers which are used in the agricultural set up.

Lime is also used for common fish disease. Formalin apparently reacts with ammonia to form hexamethylenetriamine and possibly formamide, a toxic substance to aquatic ecosystem. Other researchers have also reported use of such chemicals in pond culture and in hatchery operations. The use of Efinol for stress management and a variety of disinfectants in different aquaculture operations in Bangladesh. These were mostly used in hatchery, grow-out systems and cleaning of for equipment and materials to maintain hygiene and to control pathogen load as also observed in the present survey.

A large number of algal blooms occur in aquaculture ponds, and they are frequently catastrophic. In fish ponds, nutrient enrichment caused by the addition of fertilizers and additional feeding results in eutrophication, which is characterized by the development of thick algal blooms on a regular basis (Padmavathi and Prasad, 2007; Rodgers, 2008; Trottet et al., 2021). Removing the phytoplankton bloom is one of the challenges in aquaculture setup due to it works as primary producers in the pond. The farmers use some bloom cleaner materials including NO algae, Kill Alage and other trade name products, while urea and copper is one of the major components of the chemicals.

The use of disinfectants in both manufacturing and processing facilities is commonplace since they are effective at killing bacteria, viruses, and other pests (Ali et al., 2014; Kasai et al., 2002). There are a variety of chemicals that are extensively utilized in the aquaculture sector as disinfectants (Al-Asif et al., 2021; Chowdhury et al., 2015; Rahman et al., 2017). These chemicals are regularly employed in the majority of fish and shrimp hatcheries, grow-out facilities, and processing facilities to eliminate bacteria, viruses, and other pests that may negatively affect production. Depending on the nation, laws regulating the use of disinfectants may vary from being very easy to being quite difficult to understand (Chen et al., 2018; Kim et al., 2008; Pomaranski and Soto, 2020). The current study revealed Timsen and Pahonil were the most popular disinfectant in the aquaculture setup in the south eastern Bangladesh.

Waterborne creatures are particularly vulnerable to hydrogen sulphide $\left(\mathrm{H}_{2} \mathrm{~S}\right)$ and ammonia $\left(\mathrm{NH}_{3}-\mathrm{N}\right)$, which are poisonous gases in general. Some bacteria use the uneaten feed and organic debris on the pond bottom to produce $\mathrm{H}_{2} \mathrm{~S}$ gas, which gives the pond a rotten egg smell when it is under anaerobic conditions (Rahman et al., 2015; Sumantri et al., 2020). The study found some toxic gas reducers products along with gas removal probiotics were fairly use in the aquaculture setup. In most of the products the extract of Yucca schidigera plants were the primary ingredients (Dawood et al., 2021; Santacruz-Reyes and Chien, 2012; Yu et al., 2015).

In the fish and shrimp farming industries, aquaculturists are unaware of the magnitude of economic losses that could be avoided if $\mathrm{pH}$ levels were maintained at levels that are safe for fish. Controlling $\mathrm{pH}$ in water, in conjunction with the adoption of management practices to maintain $\mathrm{pH}$ levels at levels that are safe for fish, could help to mitigate these losses (Africa et al., 2017; Grøttum et al., 1997; Pote et al., 1990). The study area comprised of two $\mathrm{pH}$ controller chemical products which might helpful to buffer the $\mathrm{pH}$ of aquaculture setup.

Oxygenating agent are useful while the oxygen level of an aquaculture setup become depleted in a dangerous level (Chowdhury et al., 2015). In the study area we found several companies oxygenating chemical agents which were readily available in the market; while the most of the ingredients of the oxygenating agents are similar but they do marketing with different brand or trade name, including ACI OX, BIO OX, etc.

Vitamins and minerals, particularly vitamin $C$, have been shown to be stress reducers in aquaculture settings. While certain medications are extremely helpful in acting as growth promoters, farmers that want to obtain their final products as quickly as possible add various minerals and vitamins to the feed, including different vitamins and minerals premix, in order to speed up the process (Al-Asif et al., 2021; Chowdhury et al., 2015; Hasan et al., 2015; Rahman et al., 2017b). The current study revealed that, the highest number of AMDC products were growth promoter (total 59 items; 17.88\%) (Refer to, Figure 2).

Probiotics are microbial organisms and yeast preparations that have positive effects on the host body's nutrition consumption, digestion, development, and immunological response by encouraging the growth of beneficial bacteria and yeast (Hai, 2015; Martínez Cruz et al., 2012; Verschuere et al., 2000; Zorriehzahra et al., 2016). Bacillus spp., which produce spores and are Gram positive, are the primary components of the vast majority of probiotics used in fish farming (Fijan, 2014; Hlordzi et al., 2020). The use of probiotics as an environmentally acceptable alternative to antibiotics and other medicines has found widespread use in the treatment of illness in aquaculture (Farzanfar, 2006; Jahangiri and Esteban, 2018). A broad variety of beneficial bacteria strains were found in the probiotic formulations. These included Bacillus sp., Lactobacillus sp., Nitrosomonas sp., Aspergillus sp., Pseudomonas sp., Clostridium sp., Rhodococcus sp., Rhodobacter sp., and Saccharomyces cerevisiae (Rahman et al., 2017b; Shefat, 2018). Among others the validity and quality of goods containing various combinations of the probiotic organisms listed above were not confirmed despite a large number of such 
products being available on the market and in great demand. But such goods were in great demand across all aquaculture zones, suggesting that they were successful, despite the fact that their usefulness has not yet been scientifically shown.

As a result of the fact that only a few antibiotics have been approved for use in aquaculture and that precise data on their use is difficult to come by, at least two critically important antibiotics, such as the tetracyclines and oxolinic acid (a third generation quinolone), are now being used in routine practise in Bangladesh to control specific diseases and bacterial infections in the aquaculture industry, respectively (Al-Asif et al., 2021). Study of Lulijwa et al. (2020) and Rahman et al. (2017b) both reported at least 19 antibiotics were available in Bangladesh and Cumilla respectively. While the present study support the previous findings with the report of 19 antibiotics from the south eastern region of Bangladesh, comprising three popular aquaculture regions, Chandpur, Cumilla and Feni.

\section{Conclusions}

The aquaculture medicine drugs and chemicals are widely used by the farmers of south eastern Bangladesh, while the adverse effects of antimicrobial agents are simply neglected by the farmers or other stakeholders. Bioremediation, probiotics, immune-stimulants, immunization, and alternative therapeutics are examples of alternatives that may be utilized instead of antibiotics. For mitigating the harmful effects of antibiotics usage in aquaculture; policymakers, researchers, and scientists should collaborate in order to solve the problems surrounding some adverse AMDC products use in this industry.

\section{Conflict of interest}

None to declare.

\section{Authors' contribution}

Conceptualization and execution of study: Amir Hossain and Abdulla-Al-Asif; methods: Amir Hossain and Abdulla-Al-Asif; data collection: Amir Hossain; statistics and presentation: Abdulla-Al-Asif; Map preparation: Abdulla-Al-Asif; writing, original-draft preparation: Amir Hossain and Abdulla-Al-Asif; writing, review and editing: Amir Hossain, Saiful Islam, Abdulla-Al-Asif and Hafzur Rahman. All authors have read and agreed to the published version of the manuscript.

\section{References}

Adhikary RK, S Kar, A Faruk, A Hossain, MNM Bhuiyan and A Al-Asif, 2018a. Contribution of aquaculture on livelihood development of fish farmer at Noakhali, Bangladesh. Asian-Australasian J. Biosci. Biotechnol., 3: 106-121.

Adhikary RK, M Rahman and A Al-Asif, 2018b. Present status of aqua-medicines used in aquaculture at Jessore sadar upazila, Bangladesh. Asian J. Med. Biol. Res., 4: 288-297.

Adhikary MR, A Rahman, A Al-Asif and RK Adhikary, 2018c. Socio-economic status of fish retailers in Jashore sadar, Bangladesh. Asian-Australasian J. Food Saf. Secur., 2: 100-108.

Africa ADM, JCCA Aguilar, CMS Lim, PAA Pacheco and SEC Rodrin, 2017. Automated aquaculture system that regulates $\mathrm{pH}$, temperature and ammonia. HNICEM 2017 - 9th Int. Conf. Humanoid, Nanotechnology, Inf. Technol. Commun. Control. Environ. Manag., 2018: 1-6.

AftabUddin S, MG Hussain, M Abdullah Al, P Failler and BM Drakeford, 2021. On the potential and constraints of mariculture development in Bangladesh. Aquac. Int., 29: 575-593.

Ahmed GU, M Dhar, MNA Khan and JS Choi, 2007. Investigation of diseases of Thai koi, Anabas testudineus (BLOCH) from farming conditions in winter. J. Life Sci., 17: 1309-1314.

Akter S, MM Rahman, A Faruk, MNM Bhuiyan, A Hossain and A Al-Asif, 2018. Qualitative and quantitative analysis of phytoplankton in culture pond of Noakhali district, Bangladesh. Int. J. Fish. Aquat. Stud., 6: 371375.

Al-Asif A and MAB Habib, 2018. Socio-economic condition of fish farmers of Jhikargachha upazila in Jessore district, Bangladesh. Asian J. Med. Biol. Res., 3: 462-475.

Al-Asif A, A Hossain, H Hamli, S Islam and SL Kabir, 2021. Research trends of aqua medicines, drugs and chemicals (AMDC) in Bangladesh: the last decade's (2011-2020) story to tell. Asian J. Med. Biol. Res., 7: 90-106.

Al-Asif A, MA Samad, MH Rahman, MA Farid, SM Yeasmin and BMS Rahman, 2015. Socio-economic condition of fish fry and fingerling traders in greater Jessore region, Bangladesh. Int. J. Fish. Aquat. Stud., 2: 290-293. 
Alam MM and MM Haque, 2021. Presence of antibacterial substances, nitrofuran metabolites and other chemicals in farmed pangasius and tilapia in Bangladesh: Probabilistic health risk assessment. Toxicol. Reports, 8: 248-257.

Ali MM, A Al-Asif, MAI Shabuj, S Vaumik, MA Zafar and BMN Sharif, 2016. Status of polyculture Pangasius hypophthalmus with carps in Jhikargacha Upazila of Jessore district, Bangladesh. Int. J. Fish. Aquat. Stud., 4: 423-430.

Ali MM, MA Rahman, MB Hossain and MZ Rahman, 2014. Aquaculture drugs used for fish and shellfish health management in the southwestern Bangladesh. Asian J. Biol. Sci., 7: 225-232.

Anton-Pardo M and Z Adámek, 2015. The role of zooplankton as food in carp pond farming: A review. J. Appl. Ichthyol., 31: 7-14.

Assefa A and F Abunna, 2018. Maintenance of fish health in aquaculture: Review of epidemiological approaches for prevention and control of infectious disease of fish. Vet. Med. Int., 5432497: 1-10.

Bayazid Y, 2016. The daudkandi model of community floodplain aquaculture in Bangladesh: A case for Ostrom's design principles. Int. J. Commons, 10: 854-877.

Bhaumik U, P Das and T Paria, 2006. Impact of plankton structure on primary productivity in two beels of West Bengal, India. Bangladesh J. Fish. Res., 10: 1-11.

Biswas C, MMM Hossain, A Al-Asif, B Sarker, MM Billah and MA Ali, 2018. Culture strategies, diseases and their mitigations in mono-sex Nile tilapia farming in Jessore sadar region, Bangladesh. Asian-Australasian J. Biosci. Biotechnol., 3: 190-200.

Bostock J, B McAndrew, R Richards, K Jauncey, T Telfer, K Lorenzen, D Little, L Ross, N Handisyde, I Gatward and R Corner, 2010. Aquaculture: Global status and trends. Philos. Trans. R. Soc. B Biol. Sci., 365: 2897-2912.

Boyd CE, LR D’Abramo, BD Glencross, DC Huyben, LM Juarez, GS Lockwood, AA McNevin, AGJ Tacon, F Teletchea, JR Tomasso, CS Tucker and WC Valenti, 2020. Achieving sustainable aquaculture: Historical and current perspectives and future needs and challenges. J. World Aquac. Soc., 51: 578-633.

Bruno DW, B Nowak and DG Elliott, 2006. Guide to the identification of fish protozoan and metazoan parasites in stained tissue sections. Dis. Aquat. Organ., 70: 1-36.

Cabello FC, HP Godfrey, A Tomova, L Ivanova, H Dölz, A Millanao and AH Buschmann, 2013. Antimicrobial use in aquaculture re-examined: Its relevance to antimicrobial resistance and to animal and human health. Environ. Microbiol., 15: 1917-1942.

Chen X, C Lai, Y Wang, L Wei and Q Zhong, 2018. Disinfection effect of povidone-iodine in aquaculture water of swamp eel (Monopterus albus). PeerJ, 2018: 1-13.

Chowdhury AA, MS Uddin, S Vaumik and A Al-Asif, 2015. Aqua drugs and chemicals used in aquaculture of Zakigonj upazilla, Sylhet. Asian J. Med. Biol. Res., 1: 336-349.

Chukwu MN and ES Afolabi, 2018. Phytoplankton abundance and distribution of fish earthen ponds in Lagos, Nigeria. J. Appl. Sci. Environ. Manag., 21: 1245.

Dawood MAO, MS Gewaily, MN Monier, EM Younis, H Van Doan and H Sewilam, 2021. The regulatory roles of yucca extract on the growth rate, hepato-renal function, histopathological alterations, and immune-related genes in common carp exposed with acute ammonia stress. Aquaculture, 534: 736287.

Diana JS, HS Egna, T Chopin, MS Peterson, L Cao, R Pomeroy, M Verdegem, WT Slack, MG BondadReantaso and F Cabello, 2013. Responsible aquaculture in 2050: Valuing local conditions and human innovations will be key to success. Bioscience, 63: 255-262.

Faruk M, H Shorna and I Anka, 2021. Use and impact of veterinary drugs, antimicrobials, and supplements in fish health management. J. Adv. Vet. Anim. Res., 8: 36-43.

Faruk MAR, MJ Alam, MMR Sarker and MB Kabir, 2004. Status of fish disease and health management practices in rural freshwater aquaculture of Bangladesh. Pakistan J. Biol. Sci., 7: 2092-2098.

Farzanfar A, 2006. The use of probiotics in shrimp aquaculture. FEMS Immunol. Med. Microbiol., 48: 149158.

Fijan S, 2014. Microorganisms with claimed probiotic properties: An overview of recent literature. Int. J. Environ. Res. Public Health, 11: 4745-4767.

Froehlich HE, CA Runge, RR Gentry, SD Gaines and BS Halpern, 2018. Comparative terrestrial feed and land use of an aquaculture-dominant world. Proc. Natl. Acad. Sci. U. S. A., 115: 5295-5300.

Grøttum JA, M Staurnes and T Sigholt, 1997. Effect of oxygenation, aeration and pH control on water quality and survival of turbot, Scophthalmus maximus (L.), kept at high densities during transport. Aquac. Res., 28: $159-164$.

Hai NV, 2015. The use of probiotics in aquaculture. J. Appl. Microbiol. 119: 917-935. 
Hasan M, M Faruk, I Anka and M Azad, 2014. Investigation on fish health and diseases in rural pond aquaculture in three districts of Bangladesh. J. Bangladesh Agric. Univ., 11: 377-384.

Hasan MT, GU Ahmed, MM Rahman and MN Alam, 2015. Study on the effect of aquaculture-drugs and chemicals on health and production of prawn (Macrobrachium rosenbergii) in Narail, Bangladesh. Asian J. Med. Biol. Res., 1: 89-94.

Hinchliffe S, A Butcher and MM Rahman, 2018. The AMR problem: demanding economies, biological margins, and co-producing alternative strategies. Palgrave Commun., 4: 142.

Hinchliffe S, A Butcher, MM Rahman, J Guilder, C Tyler and D Verner-Jeffreys, 2021. Production without medicalisation: Risk practices and disease in Bangladesh aquaculture. Geogr. J., 187: 39-50.

Hlordzi V, FKA Kuebutornye, G Afriyie, ED Abarike, Y Lu, S Chi and MA Anokyewaa, 2020. The use of Bacillus species in maintenance of water quality in aquaculture: A review. Aquac. Reports, 18: 100503.

Hoque R, SM Ahmed, N Naher, MA Islam, EK Rousham, BZ Islam and S Hassan, 2020. Tackling antimicrobial resistance in Bangladesh: A scoping review of policy and practice in human, animal and environment sectors. Plos One, 15: 1-22.

Hossain A, MAR Hossain, A Al-Asif, S Ahmed and A Satter, 2017. Fish fermentation in Lalpur, Brahmanbaria district: ecological implication and value chain analysis. Asian-Australasian J. Biosci. Biotechnol., 2: 159172.

Hossain AM, A Al-Asif, AM Zafar, TM Hossain, SM Alam and AM Islam, 2015. Marketing of fish and fishery products in Dinajpur and livelihoods of the fish retailers. Int. J. Fish. Aquat. Stud., 3: 86-92.

Hossain MB, SMN Amin, M Shamsuddin, MH Minar, 2013. Use of aqua-chemicals in the hatcheries and fish farms of greater Noakhali, Bangladesh. Asian J. Anim. Vet. Adv., 8: 401-408.

Hossain MI, MS Rahman, AKMR Amin, SI Ahmed and M Shahjahan, 2019. Effects of sumithion on growth and production of phytoplankton and zooplankton in aquaculture ponds. Iran. J. Fish. Sci., 18: 307-318.

Hossain MK, MS Haq, BK Chawkraborty, MT Hasan and SK Mazumder, 2014. Present status of aquamedicines used for fish culture at Shantahar and Adamdighi of Bogra district, Bangladesh. IOSR J. Environ. Sci. Toxicol. Food Technol., 8: 37-42.

Islam FK, A Al-Asif, M Ahmed, MS Islam, B Sarker, MA Zafar and M Rahman, 2017. Performances of resource poor households in aquaculture practices in sadar upazila, Meherpur, Bangladesh. Int. J. Fish. Aquat. Stud., 5: 281-288.

Islam MA, A Al-Asif, MA Samad, BMS Rahman, MH Rahman, A Nima and SM Yeasmin, 2014. Socioeconomic conditions of the fish farmers in Jessore, Bangladesh. Int. J. Business, Soc. Sci. Res., 2: 153-160.

Islam MM, A Barman, GK Kundu, MA Kabir and B Paul, 2019. Vulnerability of inland and coastal aquaculture to climate change: Evidence from a developing country. Aquac. Fish., 4: 183-189.

Iyaji $\mathrm{F}$ and J Eyo, 2009. Parasites and their freshwater fish host. Bio-Research, 6, 328-338.

Jahangiri L and MÁ Esteban, 2018. Administration of probiotics in the water in finfish aquaculture systems: A review. Fishes, 3: 1-13.

Kasai H, M Yoshimizu and Y Ezura, 2002. Disinfection of water for aquaculture. Fish. Sci., 68: 821-824.

Khan MA, R Begum, R Nielsen and A Hoff, 2021. Production risk, technical efficiency, and input use nexus: Lessons from Bangladesh aquaculture. J. World Aquac. Soc., 52: 57-72.

Kim SR, KH Park, D Kim, SJ Jung, SY Kang and MJ Oh, 2008. Antimicrobial effects of chemical disinfectants on fish pathogenic bacteria. Food Sci. Biotechnol., 17: 971-975.

Korhonen JJ, J Wang and J Soininen, 2011. Productivity-diversity relationships in lake plankton communities. Plos One, 6: e22041.

Kotob MH, S Menanteau-Ledouble, G Kumar, M Abdelzaher and M El-Matbouli, 2016. The impact of coinfections on fish: a review. Vet. Res., 47: 1-12.

Lafferty KD, CD Harvell, JM Conrad, CS Friedman, ML Kent, AM Kuris, EN Powell, D Rondeau and SM Saksida, 2015. Infectious diseases affect marine fisheries and aquaculture economics. Ann. Rev. Mar. Sci., 7: 471-496.

Ledesma RG, 2019. Effectiveness of predator control set-up for aquatic pest control in earthen ponds for extensive culture of Penaeus monodon (Fabricius, 1798). Philipp. J. Fish., 26: 61-65.

Leung TLF and AE Bates, 2013. More rapid and severe disease outbreaks for aquaculture at the tropics: Implications for food security. J. Appl. Ecol., 50: 215-222.

Liu C, L Tan, L Zhang, W Tian and L Ma, 2021. A review of the distribution of antibiotics in water in different regions of China and current antibiotic degradation pathways. Front. Environ. Sci., 9: 1-24.

Lulijwa R, EJ Rupia and AC Alfaro, 2020. Antibiotic use in aquaculture, policies and regulation, health and environmental risks: a review of the top 15 major producers. Rev. Aquac., 12: 640-663. 
Majumder B, MGA Sarker, MH Khan and MBR Chowdhury, 2001. Incidence of ulcer type of disease in wild fishes of Bangladesh. Bangladesh J. Fish. Res., 5: 163-168.

Martínez Cruz P, AL Ibáñez, OAH Monroy and HCS Ramírez, 2012. Use of probiotics in aquaculture. ISRN Microbiol., 2012: 1-13.

Mogi M, 2007. Insects and other invertibrate predators. J. Am. Mosq. Control Assoc., 23: 93-109.

Naylor RL, RW Hardy, AH Buschmann, SR Bush, L Cao, DH Klinger, DC Little, J Lubchenco, SE Shumway and M Troell, 2021. A 20-year retrospective review of global aquaculture. Nature, 591: 551-563.

Neela FA, MSTNA Banu, MA Rahman, MF Alam and MH Rahman, 2015. Occurrence of antibiotic resistant bacteria in pond water associated with integrated poultry-fish farming in Bangladesh. Sains Malaysiana, 44: 371-377.

Nunny L, 2020. Animal welfare in predator control: Lessons from land and sea. How the management of terrestrial and marine mammals impacts wild animal welfare in human-wildlife conflict scenarios in Europe. Animals, 10: 1-24.

Otieno NE, 2019. Economic impact of predatory piscivorous birds on small-scale aquaculture farms in Kenya. Aquac. Reports, 15: 100220.

Padmavathi P and MKD Prasad, 2007. Studies on algal bloom disasters in carp culture ponds. J. Morphol. Sci., 24: $32-43$.

Pomaranski EK and E Soto, 2020. The formation, persistence, and resistance to disinfectant of the Erysipelothrix piscisicarius biofilm. J. Aquat. Anim. Health, 32: 44-49.

Pote JW, TP Cathcart and PN Deliman, 1990. Control of high pH in aquacultural ponds. Aquac. Eng., 9: 175186.

Pravakar P, BS Sarker, M Rahman and MB Hossain, 2013. Present status of fish farming and livelihood of fish farmers in Shahrasti Upazila of Chandpur district, Bangladesh. Am. J. Agric. Environ. Sci., 13: 391-397.

Rahman H, JA Mirza, A Hossain, A Al-Asif, E Haq, P Chwakravorty and M Rahman, 2017a. Economics of fish production in paddy fields in Bangladesh. Asian J. Med. Biol. Res., 3: 379-390.

Rahman ML, M Shahjahan and N Ahmed, 2021. Tilapia farming in Bangladesh: Adaptation to climate change. Sustain., 13: 1-20.

Rahman MM, MMM Alam, SMI Khalil, SM Bari and MM Rashid, 2015. Status of chemicals and aqua drugs used in freshwater aquaculture in north-eastern Bangladesh. J. Sylhet Agric. Univ., 2: 247-256.

Rahman MZ, A Khatun, MI Kholil and MMM Hossain, 2017b. Aqua drugs and chemicals used in fish farms of Comilla regions. J. Entomol. Zool. Stud., 5: 2462-2473.

Rahman S, S Mondal and A Hossain, 2019. Agrochemicals used in freshwater aquaculture in Jhenaidah district, Bangladesh. Asian-Australasian J. Food Saf. Secur., 3: 63-76.

Ram Kumar JSH, 2006. Larvicidal efficiency of aquatic predators: A perspective for mosquito biocontrol. Zool. Stud., 45: 447-466.

Rasul MG and BC Majumdar, 2017. Abuse of antibiotics in aquaculture and it's effects on human, aquatic animal and environment. Saudi J. Life Sci., 2: 81-88.

Razeim MA, MG Farouque, MA Sarker, A Al-Asif and M Ahmed, 2017. Attitude of farmers towards Pangas farming for their livelihood improvement. Asian-Australasian J. Biosci. Biotechnol., 2: 106-119.

Reverter M, S Sarter, D Caruso, JC Avarre, M Combe, E Pepey, L Pouyaud, S Vega-Heredía, H de Verdal and RE Gozlan, 2020. Aquaculture at the crossroads of global warming and antimicrobial resistance. Nat. Commun., 11: 1-8.

Rodgers JH, 2008. Algal toxins in pond aquaculture. South. Reg. Aquac. Cent., 4605, 7.

Santacruz-Reyes RA and YH Chien, 2012. The potential of Yucca schidigera extract to reduce the ammonia pollution from shrimp farming. Bioresour. Technol., 113: 311-314.

Schar D, C Zhao, Y Wang, DGJ Larsson, M Gilbert and TP Van Boeckel, 2021. Twenty-year trends in antimicrobial resistance from aquaculture and fisheries in Asia. Nat. Commun., 12: 6-15.

Shabuj MAI, T Bairagi, Al A -Asif, O Faruq, MR Bari and MS Neowajh, 2016. Shrimp disease investigation and culture strategies in Bagerhat district, Bangladesh. Asian J. Med. Biol. Res., 1: 545-552.

Shamsuzzaman MM and TK Biswas, 2012. Aqua chemicals in shrimp farm: A study from south-west coast of Bangladesh. Egypt. J. Aquat. Res., 38: 275-285.

Shamsuzzaman MM, MMM Hoque, SJ Mitu, AF Ahamad and MS Bhyuian, 2020. The economic contribution of fish and fish trade in Bangladesh. Aquac. Fish., 5: 174-181.

Shamsuzzaman MM, MM Islam, Tania NJ, AMM Abdullah, PP Barman and X Xu, 2017. Fisheries resources of Bangladesh: Present status and future direction. Aquac. Fish., 2: 145-156.

Sharif BMN and A Al-Asif, 2015. Present status of fish hatchlings and fry production management in greater 
Jessore, Bangladesh. Int. J. Fish. Aquat. Stud., 2: 123-127.

Sharif BN, A Al-Asif, S Vaumik, MA Zafar, MM Islam and MA Samad, 2015. Socio-economic condition of fish farmer and trader at the village of Pitamborpur in Chaugachha Upazilla in Jessore, Bangladesh. Int. J. Fish. Aquat. Stud., 3: 212-217.

Sharker MR, KR Sumi, MJ Alam, MM Rahman, Z Ferdous, MM Ali and MR Chaklader, 2014. Drugs and chemicals used in aquaculture activities for fish health management in the coastal region of Bangladesh. Int. J. Life Sci. Biotechnol. Pharma Res., 3: 49-58.

Shefat SHT, 2018. Use of probiotics in shrimp aquaculture in Bangladesh. Acta Sci. Microbiol., 1: 20-27.

Siddika F, M Shahjahan and M Rahman, 2013. Abundance of plankton population densities in relation to bottom soil textural types in aquaculture ponds. Int. J. Agric. Res. Innov. Technol., 2: 56-61.

Siddique AB, M Moniruzzaman, S Ali, MN Dewan, MR Islam, MS Islam, MB Amin, D Mondal, AK Parvez and ZH Mahmud, 2021. Characterization of pathogenic Vibrio parahaemolyticus isolated from fish aquaculture of the Southwest coastal area of Bangladesh. Front. Microbiol., 12: 1-15.

Sipaúba-Tavares L, A Donadon and R Milan, 2011. Water quality and plankton populations in an earthen polyculture pond. Brazilian J. Biol., 71: 845-855.

Sumantri I, L Buchori, FAW Mukti, F Ramadhani and DD Anggoro, 2020. Study of the rate of adsorption of toxic gases in shrimp ponds using Sukabumi natural zeolite. AIP Conf. Proc., 2197: 120005.

Sunny AR, SH Prodhan, M Ashrafuzzaman, MH Mithun, M Hussain, MT Alam, A Rashid and MM Hossain, 2021. Fisheries in the context of attaining Sustainable Development Goals (SDGs) in Bangladesh: COVID19 impacts and future prospects. Sustainability, 13: 1-35.

Thornber K, D Huso, MM Rahman, H Biswas, MH Rahman, E Brum and CR Tyler, 2019. Raising awareness of antimicrobial resistance in rural aquaculture practice in Bangladesh through digital communications: a pilot study. Glob. Health Action, 12: 1734735.

Toufique KA and B Belton, 2014. Is aquaculture pro-poor? empirical evidence of impacts on fish consumption in Bangladesh. World Dev., 64: 609-620.

Trottet A, C George, G Drillet and FM Lauro, 2021. Aquaculture in coastal urbanized areas: A comparative review of the challenges posed by Harmful Algal Blooms. Crit. Rev. Environ. Sci. Technol., 1: 1-42.

Ullah MA, MA Naeem, A Hossain, A Al-Asif and MR Hasan, 2020a. Categorization and distribution of aquachemicals used in coastal farming of south-eastern part of Bangladesh. J. Aquac. Res. Dev., 11: 1-7.

Ullah MA, M Rahman, MR Hasan, MM Hasan and MS Hossain, 2020b. Present status and economic benefit of integrated fish farming system in Noakhali region, Bangladesh. Asian J. Med. Biol. Res., 6: 525-529.

Vaumik S, SK Sarker, MS Uddin, MT Alam, A Satter and A Al-Asif, 2017. Constraints and prospects of fish farming in Lalmonirhat district. Int. J. Business, Soc. Sci. Res., 5: 201-210.

Verschuere L, G Rombaut, P Sorgeloos and W Verstraete, 2000. Probiotic bacteria as biological control agents in aquaculture. Microbiol. Mol. Biol. Rev., 64: 655-671.

Watts JEM, HJ Schreier, L Lanska and MS Hale, 2017. The rising tide of antimicrobial resistance in aquaculture: Sources, sinks and solutions. Mar. Drugs, 15: 1-16.

Yu X, E Dimitriou, S Konstantinos, V Markogianni and D Politi, 2015. Effects of yucca shidigera extract on the reduction of ammonia concentration in lake Koumoundourou. J. Ecol. Eng., 16: 1-7.

Zorriehzahra MJ, ST Delshad, M Adel, R Tiwari, K Karthik, K Dhama and CC Lazado, 2016. Probiotics as beneficial microbes in aquaculture: an update on their multiple modes of action: a review. Vet. Q., 36: 228241. 